\title{
Climate change impacts on the seasonality and generation processes of floods - projections and uncertainties for catchments with mixed snowmelt/rainfall regimes
}

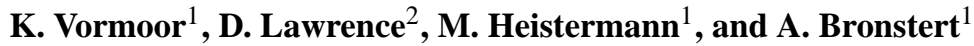 \\ ${ }^{1}$ Institute of Earth and Environmental Science, University of Potsdam, Postdam, Germany \\ ${ }^{2}$ Norwegian Water Resources and Energy Directorate (NVE), Oslo, Norway
}

Correspondence to: K. Vormoor (kvormoor@uni-potsdam.de)

Received: 22 May 2014 - Published in Hydrol. Earth Syst. Sci. Discuss.: 13 June 2014

Revised: 14 January 2015 - Accepted: 22 January 2015 - Published: 12 February 2015

\begin{abstract}
Climate change is likely to impact the seasonality and generation processes of floods in the Nordic countries, which has direct implications for flood risk assessment, design flood estimation, and hydropower production management. Using a multi-model/multi-parameter approach to simulate daily discharge for a reference (1961-1990) and a future (2071-2099) period, we analysed the projected changes in flood seasonality and generation processes in six catchments with mixed snowmelt/rainfall regimes under the current climate in Norway. The multi-model/multi-parameter ensemble consists of (i) eight combinations of global and regional climate models, (ii) two methods for adjusting the climate model output to the catchment scale, and (iii) one conceptual hydrological model with 25 calibrated parameter sets. Results indicate that autumn/winter events become more frequent in all catchments considered, which leads to an intensification of the current autumn/winter flood regime for the coastal catchments, a reduction of the dominance of spring/summer flood regimes in a high-mountain catchment, and a possible systematic shift in the current flood regimes from spring/summer to autumn/winter in the two catchments located in northern and south-eastern Norway. The changes in flood regimes result from increasing event magnitudes or frequencies, or a combination of both during autumn and winter. Changes towards more dominant autumn/winter events correspond to an increasing relevance of rainfall as a flood generating process (FGP) which is most pronounced in those catchments with the largest shifts in flood seasonality. Here, rainfall replaces snowmelt as the dominant FGP primarily due to increasing temperature. We further analysed
\end{abstract}

the ensemble components in contributing to overall uncertainty in the projected changes and found that the climate projections and the methods for downscaling or bias correction tend to be the largest contributors. The relative role of hydrological parameter uncertainty, however, is highest for those catchments showing the largest changes in flood seasonality, which confirms the lack of robustness in hydrological model parameterization for simulations under transient hydrometeorological conditions.

\section{Introduction}

The hydrological cycle is likely to intensify due to climate change (IPCC, 2007; Seneviratne et al., 2012), and a recent study indicates that global warming has caused more intense precipitation over the last century on the global scale (Benestad, 2013). These changes will, in turn, have direct implications for flood risk. For mountainous and Nordic regions, changes in the ratio of rainfall and snowfall due to temperature rise are of special interest since they have direct implications for flood seasonality and for the dominant processes generating flood discharge.

A coherent picture of observed positive annual and winter streamflow trends for the Nordic countries (Stahl et al., 2010; Wilson et al., 2010) has been linked to a pattern of generally increasing mean and extreme precipitation (Bhend and von Storch, 2007; Dyrrdal et al., 2012). Regarding flood seasonality, neither significant trends towards higher autumn floods as a result of increasing autumn rainfall, nor system- 
atic trends in spring flood magnitudes are yet detected (Wilson et al., 2010). The same study found, however, a strong trend towards earlier spring floods at many stations. This is likely due to the observed increase in mean annual temperature during the last century, which has been reported to be $0.8^{\circ} \mathrm{C}$, with the strongest decadal temperature rise during the spring season (Hanssen-Bauer et al., 2009).

Climate projections for Norway for the end of the 21 st century indicate increasing temperatures $\left(2.3-4.6^{\circ} \mathrm{C}\right)$ and precipitation (5-30\%) with the largest temperature increase during winter in northern Norway, and the largest precipitation increase during autumn and winter on the west coast (Hanssen-Bauer et al., 2009). Extreme precipitation is also likely to increase for all seasons across the whole of Norway (Beniston et al., 2007; Hanssen-Bauer et al., 2009; Seneviratne et al., 2012), although such projections are highly uncertain (Fowler and Ekström, 2009). Changes in temperature and precipitation regimes will have direct implications for the snow regime in Norway. For mountainous areas and in northern Norway where mean winter temperature is a few degrees below 0 , snow depth is observed to have increased in recent decades (Dyrrdal et al., 2013) and climate projections suggest further increases until 2050 (Hanssen-Bauer et al., 2009). In other parts of Norway snow depths are projected to decrease. Towards the end of the 21st century, a decrease in snow depths and a shorter snow season are projected for the whole of the country due to temperature rise.

For the Nordic countries, several previous studies have investigated the hydrological impacts of climate change (e.g. Andréasson and Bergström, 2004; Roald, 2006; Beldring et al., 2008; Veijalainen et al., 2010; Lawrence and Hisdal, 2011; Lawrence and Haddeland, 2011). For Norway, Lawrence and Hisdal (2011) studied the changes in flood frequency in 115 Norwegian catchments and found coherent regional patterns of directional change in flood magnitudes under a future climate: the magnitudes of the 200-year flood, for example, is likely to increase in catchments in western and much of coastal Norway where flood generation is dominated by autumn/winter rainfall, while magnitudes are expected to decrease in the snowmelt-dominated catchments in inland areas and parts of northern Norway. This regional pattern reflects systematic changes in climate forcing, which lead to changes in hydrological flooding in terms of both seasonal prevalence and generation process (rainfall vs. snowmelt). There are, however, many catchments which are transitional between rainfall-dominated vs. snowmelt-dominated flood regimes, and interpretation of the likely direction of change in the magnitude of future floods is more difficult. In addition, such catchments may be subject to a shift in the flood season under a future climate. Considering the uncertainty in the projections for future (extreme) precipitation and subsequent flooding conditions (Bronstert et al., 2007), Blöschl et al. (2011) argue that seasonal change in the distribution of floods is the key to understanding climate change impacts on flooding rather than changes in flood magnitudes and fre- quencies. Changes in the underlying flood generating processes (FGPs) are correspondingly important for interpreting the direction (i.e. increase vs. decrease) of climate change impacts on future floods. Therefore, we aim to study in detail the changing role of rainfall and snowmelt under future climate scenarios to aid in understanding flood regime changes in catchments which already show mixed snowmelt/rainfall flood regimes in today's climate.

For practical purposes, changes in flood seasonality have implications for future flood risk assessments, design flood estimations, and hydropower production management. In Norway, where hydropower represents about $96 \%$ of the total electricity production, flood seasonality impacts reservoir management and accordingly hydropower production. In addition, design flood estimates for dam safety require that the season for the highest flood risk is assessed (e.g. Midttømme et al., 2011) and changes in the dominant flood season under a future climate have significant implications for these assessments. Despite the relevance of this issue, there has not yet been a detailed investigation of climate change impacts on future flood seasonality and the process-related factors contributing to those changes in Norway.

In this study, we investigate the impact of climate change on flood seasonality and the related FGPs in six Norwegian catchments representing different geographical and climatological conditions. The catchments were selected such that both rainfall and snowmelt sometimes play a role in the generation of high-flow events under the current climate; we investigate how the balance between these two flood generating factors changes. We apply a multi-model/multiparameter ensemble to develop a range of hydrological projections which allows us to consider some of the uncertainties associated with such an analysis (e.g. Hall et al., 2014). The multi-model/multi-parameter ensemble used here consists of eight combinations of global and regional climate models (GCM/RCM combinations), two methods for locally adjusting the climate model output data to the catchment scale, and hydrological modelling implemented with the HBV model based on 25 calibrated parameter sets. Our particular research questions are (1) how might the existing patterns of flood seasonality change under a future climate? (2) How are shifts in seasonality related to changes in the magnitude vs. changes in the frequency of events? (3) Are changes in flood seasonality associated with changes in the dominant FGPs? (4) What is the relative importance of the different ensemble components in contributing to the overall variance as a measure of the uncertainty in the projected changes?

\section{Study area}

\subsection{Climate and runoff regimes in Norway}

Climatological gradients driven by latitude, topography and location relative to the coastal zone control the spatial pat- 
tern of temperature and precipitation regimes in Norway. The mean annual temperature varies from $7.7^{\circ} \mathrm{C}$ at the south-western coast to about $-3{ }^{\circ} \mathrm{C}$ in the inland areas of northern Norway and the high-altitude areas in central Norway (Hanssen-Bauer et al., 2009). Mean annual precipitation varies from about $300 \mathrm{~mm}$ in north-eastern and central Norway to more than $3500 \mathrm{~mm}$ in western Norway (HanssenBauer et al., 2009). Seasonally, western Norway receives the largest precipitation volumes during the autumn and winter months, while the more inland region in the east receives these during the summer.

Mean annual runoff generally reflects the pattern of mean annual precipitation, and runoff coefficients tend to be high due to low evapotranspiration. However, due to differences in the temperature regime, snowpack volumes and the snow season vary considerably across the country, which leads to differences in the regional importance of snowmelt as a runoff generation process. Hence, two basic patterns in runoff regimes can be distinguished in Norway: (i) regions in inland and northernmost Norway with prominent high flows during spring and summer predominantly due to snowmelt, and (ii) regions in western Norway and in coastal regions with prominent high flows during autumn and winter predominantly due to rainfall. There are, though, numerous variations reflecting local climate as well as transitional, mixed, regimes. In addition, catchments with sources in high mountain areas can experience peak flows in late summer, due to glacier melt. A comprehensive classification of runoff regimes based on the seasonal occurrence of monthly high and low flows is given by Tollan (1975) and reviewed in Gottschalk et al. (1979). This classification defines five types of flood regimes for the Nordic countries and give detailed distinctions between possible combinations of high-flow and low-flow periods. However, in order to develop a broad picture of flood seasonality, it is most useful to apply the simple distinction between two high-flow seasons (spring/summer vs. autumn/winter) and to distinguish rainfall vs. snowmelt as the most fundamental flood generation processes.

\subsection{Study catchments}

Changes in flood seasonality and the FGPs were investigated in six catchments distributed across Norway: Krinsvatn, Fustvatn, Øvrevatn, Junkerdalselv, Atnasjø, and Kråkfoss (Fig. 1). These catchments represent some of the variability in climate conditions across the country. The focus in this work, however, is on catchments which already exhibit some tendency for both snowmelt- and rainfall-dominated flood regimes. Therefore, a full range of climatic conditions is not represented nor are some regions (e.g. western and southern coastal Norway) included in this analysis. In addition, the sample includes only catchments of moderate size which are suitable for hydrological modelling with a daily time step.
The catchments considered are largely unaffected by damming or regulation (Petterson, 2004), and anthropogenic land use (changes) can be neglected since land use constitutes only between 0 and $1 \%$ of land cover in all catchments except Kråkfoss (11\%). The catchments are included in the benchmark data set for climate change studies for Norway and are classified as suitable for daily analyses of flood discharge (Fleig et al., 2013). The six catchments are mesoscale catchments and vary in size from $207 \mathrm{~km}^{2}$ (Krinsvatn) to $526 \mathrm{~km}^{2}$ (Fustvatn). Further catchment characteristics including elevation, land cover, as well as mean annual precipitation and runoff are given in Table 1. Figure 1 displays flood roses to illustrate the magnitudes of the annual maximum floods (AMFs) from observed daily series by their Julian date of occurrence. These plots indicate the flood seasonality for the six catchments for the period 1961-1990 (except for Kråkfoss where the observed time series begins in 1966)

Although Krinsvatn and Fustvatn have the lowest elevations amongst the catchments, they receive a considerably higher annual precipitation (2291 and $3788 \mathrm{~mm}$, respectively) due to their coastal locations. Correspondingly, the catchments have large average annual runoff values, and both the majority of and the largest AMFs occur during late autumn and winter, representing rainfall-dominated flood generation. However, both catchments are also subject to snowmelt floods, as indicated by the comparatively smaller events occurring during spring.

Øvrevatn, Junkerdalselv and Atnasjø show the highest median elevation and elevation ranges, but differ considerably with respect to annual precipitation and runoff volumes. $\varnothing v$ revatn and Atnasjø, though being the highest catchments within this comparison, receive considerably less precipitation ( 832 and $840 \mathrm{~mm}$, respectively) due to their rain shadow locations. Junkerdalselv, being located further inland near the Swedish border, is not directly influenced by rain shadow effects and has annual precipitation and runoff volumes that are about 3 times larger than at $\varnothing$ vrevatn and Atnasjø. Because of the temperature regime, all three catchments receive a large portion of the annual precipitation as snow so that the majority of and the largest AMFs occur during spring and summer (May-July, Fig. 1), with snowmelt as the dominant FGP.

Kråkfoss, located inland of the Oslofjord, is the southernmost catchment within this study and has a slightly different flood regime. There is no definite seasonal prevalence for the AMFs; one-half of the events occur during spring and summer, the other half during autumn and early winter. The magnitude of the autumn events tends to be slightly larger than those occurring during spring. Snowmelt plays a definite role in the early events in the spring/summer period, whilst the events during autumn are triggered by rainfall. In addition, it is important to note that for catchments dominated by snowmelt floods, the largest events almost always represent a combination of snowmelt and heavy rainfall. Similarly, 

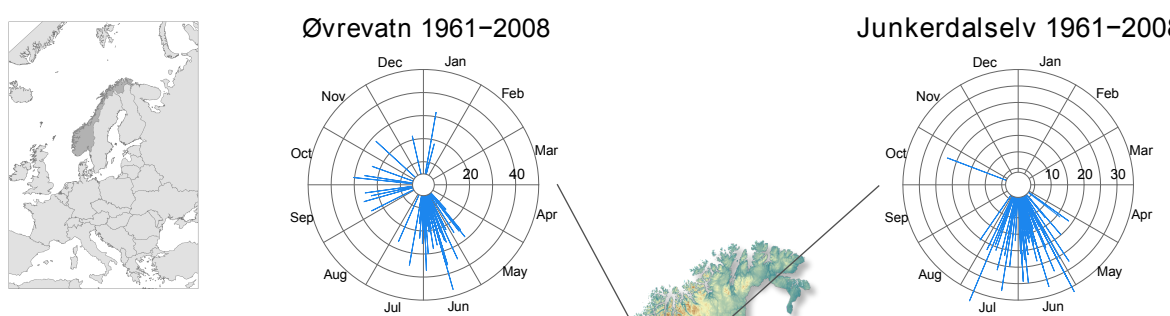

Fustvatn 1961-2008

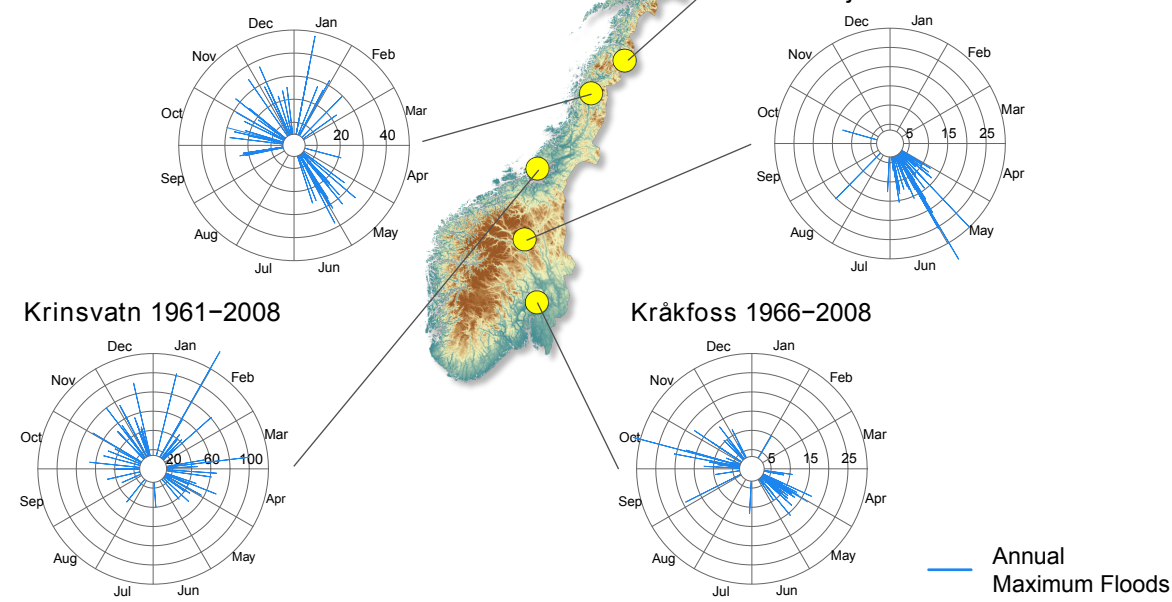

Atnasjø 1961-2008

Figure 1. The location of the six study catchments and their current flood regime demonstrated by flood roses indicating the magnitude and timing of observed annual maximum floods. Values are given as specific discharge $\left(\mathrm{mm} \mathrm{day}^{-1}\right)$. Note that secondary annual flood peaks can occur during contrasting seasons.

Table 1. Characteristics of the six study catchments.

\begin{tabular}{lllllll}
\hline $\begin{array}{l}\text { Catchment } \\
\text { property }\end{array}$ & Krinsvatn & Fustvatn & $\emptyset$ vrevatn & Junkerdalselv & Atnasjø & Kråkfoss \\
\hline $\begin{array}{l}\text { Area }\left(\mathrm{km}^{2}\right) \\
\begin{array}{l}\text { Median elevation } \\
(\mathrm{m} \text { a.s.1.) }\end{array}\end{array}$ & 207 & 526 & 525 & 420 & 463 & 433 \\
$\begin{array}{l}\text { Elevation range } \\
\text { (ma.s.1.) }\end{array}$ & $87-629$ & $39-812$ & $145-1636$ & $117-1703$ & $701-2169$ & $105-803$ \\
$\begin{array}{l}\text { Average annual } P \\
\text { (mm) }\end{array}$ & 2291 & 3788 & 832 & 3031 & 840 & 2092 \\
$\begin{array}{l}\text { Average annual } Q \\
\text { (mm) }\end{array}$ & 1992 & 3017 & 564 & 2722 & 672 & 1798 \\
$\begin{array}{l}\text { Land cover, } \% \\
\text { lake }\end{array}$ & 8 & 6 & 10 & 0 & 2 & 4 \\
$\begin{array}{l}\text { Land cover, \% } \\
\text { glacier }\end{array}$ & 0 & $<1$ & 4 & 1 & 205 & 0 \\
$\begin{array}{l}\text { Land cover, } \% \\
\text { forest }\end{array}$ & 20 & 38 & 23 & 25 & 20 & 76 \\
$\begin{array}{l}\text { Land cover, } \% \\
\text { marsh and bog }\end{array}$ & 9 & 5 & 1 & 1 & 2 & 5 \\
$\begin{array}{l}\text { Land cover, } \% \\
\text { sparse vegetation } \\
\text { above treeline }\end{array}$ & 57 & 37 & 57 & 63 & 69 & 0 \\
$\begin{array}{l}\text { Anthropogenic } \\
\text { land use (\%) }\end{array}$ & 0.4 & 0.0 & 0.7 & 0.5 & 0.4 & 11.2 \\
\hline
\end{tabular}


most of the catchments dominated by rainfall-induced flooding have periods in which a transient snow cover also may contribute to runoff during rainfall. Therefore, for this study it is useful to define a third FGP ("rainfall + snowmelt"), which occurs to varying degrees in all six catchments considered.

The dominant land cover types in the six catchments are either exposed (crystalline) bedrock with sparse vegetation above tree line (Atnasjø, $69 \%$; Junkerdalselv, $63 \%$; Krinsvatn, $57 \%$; Øvrevatn, $57 \%$ ) or boreal forest (Kråkfoss, $76 \%$; Fustvatn, $38 \%$ ). Soils in all catchments are rather thin and poorly developed, and large, regional groundwater storage in aquifers is virtually non-existent due to the crystalline bedrock. However, in most catchments, surface water in the form of lakes, marshes and bogs can lead to water retention and, in some cases, significant attenuation of flood peaks.

\section{Data and methods}

\subsection{Modelling strategy}

The analyses of changes in flood seasonality and their associated FGPs are based on a multi-model/multi-parameter ensemble approach consisting of (i) eight GCM/RCM combinations, (ii) two methods for adjusting the temperature and precipitation outputs of the climate models at the catchment scale, and (iii) the HBV hydrological model with 25 different parameter sets for considering hydrological parameter uncertainty. It has become good practice to include more than one model for each member within the model chain to derive a range of possible projections and to allow drawing conclusions about the uncertainty that is associated by such approaches. We have only used one hydrological model in our ensemble setup; this is supported by Velázquez et al. (2013), who conclude that the use of multiple hydrological models in climate impact studies is important for the study of low flows and means, but not for high flows, as various lumped and distributed models lead to very similar results. Moreover, the HBV model has been widely applied in the Nordic countries since it represents a suitable conceptual representation of the dominant runoff generating processes and does not impose excessive data requirements. The following subsections describe the individual components of the ensemble in more detail.

\subsection{Climate projections}

The climate projections for precipitation and temperature chosen for the hydrological simulations are based on eight GCM/RCM combinations (Table 2) from the EU FP6 ENSEMBLES project (van der Linden and Mitchell, 2009). The spatial resolution of all RCMs considered is $0.22^{\circ}$ (approximately $25 \mathrm{~km}$ ), and projections of daily values are available for the period 1950-2099. Within this study, two periods are compared: a reference period (1961-1990) for which the
Table 2. The GCM/RCM combinations from ENSEMBLES used for the hydrological projections. The full names of the institute abbreviations are SMHI - Swedish Meteorological and Hydrological Institute, met.no - the Norwegian Meteorological Institute, KNMI The Royal Netherlands Meteorological Institute, MPI - Max Planck Institute for Meteorology (Germany), ICTP - International Centre for Theoretical Physics (Italy), METEO-HC - The Met Office Hadley Centre (UK).

\begin{tabular}{lll}
\hline $\begin{array}{l}\text { Global } \\
\text { climate model } \\
(\text { GCM })\end{array}$ & $\begin{array}{l}\text { Regional } \\
\text { climate model } \\
(\text { RCM })\end{array}$ & Institute \\
\hline BCM & $\begin{array}{l}\text { RCA } \\
\text { HIRHAM }\end{array}$ & $\begin{array}{l}\text { SMHI } \\
\text { met.no }\end{array}$ \\
\hline ECHAM5 & $\begin{array}{l}\text { RACMO } \\
\text { REMO } \\
\text { RegCM }\end{array}$ & $\begin{array}{l}\text { KNMI } \\
\text { MPI } \\
\text { ICTP }\end{array}$ \\
\hline HadCM3Q0 & HadRM3Q0 & METEO-HC \\
\hline HadCM3Q3 & HadRM3Q3 & METEO-HC \\
\hline HadCM3Q16 & HadRM3Q16 & METEO-HC \\
\hline
\end{tabular}

GCM/RCM combinations are driven by the IPCC-AR4 scenario C20, and a future period (2071-2099) for which the climate model combinations are driven by the SRES A1B scenario, which represents intermediate greenhouse gas emissions until the end of the 21st century (IPCC, 2000, 2007). We only focus on the far future period since the change signals are more pronounced by this time. We selected the eight RCMs from ENSEMBLES that are nested within as many different GCMs as possible to minimize the interdependency between the climate model outputs used (Sunyer et al., 2013).

\subsection{Local adjustment methods (LAMs)}

It is widely acknowledged that the RCM outputs for the variables of interest (in our case precipitation and temperature) are biased due to limited process description, biased fluxes at the RCM margins and insufficient spatial resolution relative to the catchment scale (Engen-Skaugen et al., 2007). Therefore, data post-processing is necessary to bridge the gap between the large-scale climate model and the local hydrological processes (e.g. Maraun et al. 2010; Chen et al., 2011). Considerable progress has been made during recent years regarding the development and improvement of such methods and Hanssen-Bauer et al. (2005), Fowler et al. (2007), Maraun et al. (2010), and Teutschbein and Seibert (2012) give comprehensive reviews on available approaches.

Amongst the LAMs, a useful distinction can be made between statistical downscaling and bias correction methods. In this study two different LAMs were applied: (i) empirical quantile mapping (Boé et al., 2007; Gudmundsson et al., 2012) representing a bias correction method, and (ii) ex- 
panded downscaling (Bürger, 1996; Bürger et al., 2009) which is a type of statistical downscaling.

\subsubsection{Empirical quantile mapping (EQM)}

EQM is a bias correction method that seeks a transfer function $(h)$ to adjust RCM data so that it is in better agreement with observations. By adjusting the quantiles of the biased RCMs $\left(x_{\mathrm{m}}\right)$ to those of the locally observed data $\left(x_{\mathrm{o}}\right)$, the bias-corrected distribution of $x_{\mathrm{m}}$ should match the distribution of $x_{0}$, such that

$x_{\mathrm{o}}=h\left(x_{\mathrm{m}}\right)=F_{\mathrm{o}}^{-1}\left(F_{\mathrm{m}}\left(x_{\mathrm{m}}\right)\right)$,

where $F_{\mathrm{m}}$ is the empirical cumulative distribution function (eCDF) of $x_{\mathrm{m}}$, and $F_{\mathrm{o}}^{-1}$ is the inverse eCDF (the quantile function) corresponding to $x_{0}$. Based on the assumption that the shortcomings of the climate model are the same for the reference and future periods (van Roosmalen et al., 2011) and that the transfer function is stationary in time (Maraun et al., 2010), the function is applied to bias-correct projections from RCMs for both the reference and future periods.

For Norway, Gudmundsson et al. (2012) found that nonparametric transfer methods (as EQM) performed best for the bias correction of precipitation compared to parametric and distribution-derived transformations. For temperature, we found the same ranking though the differences are not as large as for precipitation. Therefore, EQM was considered as a suitable LAM for the correction of daily precipitation and temperature values for this study. The method was implemented as an add-on package (qmap; Gudmundsson, 2014) for the statistical programming environment $R$ ( $R$ Core Team, 2012). Bias correction was performed on daily values for the full year, without distinguishing seasons, following work of Piani et al. (2009) which illustrated that the correction without seasonal subsampling performs remarkably well.

\subsubsection{Expanded downscaling (XDS)}

XDS is a statistical downscaling approach and, as such, it maps large-scale atmospheric fields (the predictors $-x$ ) to local data (the predictands $-y$ ). XDS has been applied for various purposes, e.g. for early flood warning (Bürger et al., 2009), downscaling extreme precipitation projections (Dobler et al., 2013), and hydrological impact studies (Dobler et al., 2012a).

At its core, XDS is based on multiple linear regression (MLR) which leads to minimizing the least square errors. The drawback of MLR, however, is that local climate variability will be smoothed significantly, which has strong implications for the simulation of extremes. To overcome this limitation, XDS adds an additional condition for retaining local co-variability between the variables:
$\mathrm{XDS}=\arg \min _{Q}|| \boldsymbol{x} \mathbf{Q}-\boldsymbol{y} \|$, subjected to $\mathbf{Q}^{\prime} \boldsymbol{x}^{\prime} \boldsymbol{x} \mathbf{Q}=\boldsymbol{y}^{\prime} \boldsymbol{y}$,

such that XDS is the solution of the error-minimizing ma$\operatorname{trix} \mathbf{Q}(x \mathbf{Q}-\boldsymbol{y})$ which is found amongst those that preserve the local covariance $\left(\mathbf{Q}^{\prime} \boldsymbol{x}^{\prime} \boldsymbol{x} \mathbf{Q}=\boldsymbol{y}^{\prime} \boldsymbol{y}\right)$. This approach is supposed to improve the estimation of extreme events, at the cost of a larger mean error as compared to conventional MLR.

For the present study, we used humidity, wind fields, temperature, and precipitation characteristics as predictor fields. XDS was calibrated on the RCM atmospheric fields driven by the ECMWF ERA-40 reanalysis (Uppala et al., 2005) for the period 1961-1980, and then applied to downscale the RCM outputs for the reference and future scenarios.

\subsection{The HBV model}

The analysis of climate change impacts at the catchment scale is based on daily streamflow simulated by the lumped, conceptual HBV model (Bergström, 1976, 1995), forced by the locally adjusted RCM data. In this study we apply the "Nordic" version of the model (Sælthun, 1996), which incorporates a snow module with 10 equal area height zones, such that snow accumulation and melting has a semi-distributed structure. For each equal area height zone, snow accumulation and melting is calculated individually, and the mean is finally used to represent the snow dynamics for each catchment. The principal advantage of the HBV model relative to more physically based models are that it only requires precipitation and temperature as climatological input. These are given as catchment mean values for the catchment centroid. Input data for precipitation and temperature are modified for the snow routine by three parameters defining the precipitation altitude gradient, and the temperature gradients for dry and wet days, respectively.

The HBV model was calibrated for each catchment using daily-averaged discharge data. Excepting Kråkfoss, where observed data are only available since 1966, the entire reference period (1961-1990) was used for model calibration. The use of such a long calibration period increases the chance that all relevant processes are covered (Merz et al., 2009). The model calibration uses the dynamically dimensioned search (Tolson and Shoemaker, 2007) (DDS) which is a global optimization algorithm for the calibration of multiparameter models. A modified version of the Nash-Sutcliffe efficiency (NSE) was used as the objective function so as to focus on matching the high-flow events

$\mathrm{NSE}_{w}=1-\frac{\sum_{i=1}^{n} Q_{\mathrm{obs}}\left(Q_{\mathrm{sim}}-Q_{\mathrm{obs}}\right)^{2}}{\sum_{i=1}^{n} Q_{\mathrm{obs}}\left(Q_{\mathrm{sim}}-\overline{Q_{\mathrm{obs}}}\right)^{2}}$,

where $Q_{\text {obs }}$ represents the observed discharges and $Q_{\text {sim }}$ represents the modelled discharges. The squared differences in the numerator and denominator are weighted by the observed 
discharge. A mismatch between high observed and simulated discharges is, therefore, penalized proportionally to the observed discharge value.

To account for parameter uncertainty, 25 best-fit parameter sets were identified and included for the hydrological simulations. Fifteen free parameters were subjected to the calibration by DDS, which was setup to 1200 model calls. The best-performing parameter set was taken directly from the DDS calibration. The remaining 24 parameter sets were identified by a subsequent Monte Carlo simulation with another 1200 model calls using a narrowed range in the parameter values which was defined by the range of parameter values of the $36(3 \%)$ best parameter sets identified by DDS. In that way, the effects of interdependency between the parameter sets are minimized.

\subsection{Change analysis}

The extreme events of the daily streamflow simulations were extracted using a peak over threshold (POT) approach, which leads to a more comprehensive selection of events (in terms of timing and flood processes) compared the block maximum method (i.e. AMF) (Lang et al., 1999). The threshold was set to the 98.5 streamflow percentile for both the control and future periods. Independency of events was achieved by enforcing that (i) only one event can occur within twice the normal flood duration (which is catchment specific) and (ii) that only the largest event will be considered if more than one peak is identified within that time period. The normal flood duration has been derived, for each of the six catchments considered, by a simple experiment using the HBV model. Each catchment was artificially drained to baseflow conditions before twice the amount of annual rainfall was added to completely saturate the catchment again. Concentration and recession time to baseflow were estimated from the resulting hydrographs. The normal flood duration for the catchment was then defined as the sum of the concentration and recession times.

\subsubsection{Changes in flood seasonality}

Detected POT events were divided into two seasons reflecting the basic flood regimes described in Sect. 2.1: (i) the spring/summer period from March to August, which is associated with snowmelt as an important FGP under the current climate, and (ii) the autumn/winter period from September to February, which is associated with rainfall as the most important FGP. To quantify the seasonality of flood events, we define a seasonality index $S_{\mathrm{D}}$ :

$S_{\mathrm{D}}=\frac{\mathrm{POT}_{\text {Sep-Feb }}}{\mathrm{POT}_{\text {all }}}-\frac{\mathrm{POT}_{\text {Mar-Aug }}}{\text { POT }_{\text {all }}}$,

where the first term describes the ratio between the flood peaks $\left(\mathrm{m}^{3} \mathrm{~s}^{-1}\right)$ of the POT events occurring within the period September-February over all POT events, and the second term describes the ratio between the POT events occurring within March-August over all POT events. The index ranges from -1 to +1 : negative numbers indicate dominant events during spring/summer while positive numbers indicate dominant events during autumn/winter. $S_{\mathrm{D}}$ was estimated for each ensemble member for both the reference and the future periods. The difference in $S_{\mathrm{D}}$ between the future and the reference periods is an indicator of changes in flood seasonality. In addition, the magnitudes and frequencies of the detected spring/summer and autumn/winter events were analysed for the reference and the future periods. The changes in magnitudes and relative frequencies of the events within each season aid in explaining changes in flood seasonality.

\subsubsection{Changes in FGPs}

Each POT event was analysed to determine the dominant contribution to flood discharge. This contribution has been inferred from the runoff components simulated by the HBV model. A simple water balance approach was used to classify the events into floods generated by (i) "rainfall", (ii) "rainfall + snowmelt" and (iii) "snowmelt". The classification is based on the relative contribution of the volumes of rainfall and snowmelt to the flood event discharge: an event was classified as rainfall if the contribution of rainfall was larger than two-thirds, and classified as snowmelt if rainfall contribution was smaller than one-third. Other events were classified as rainfall + snowmelt. Note that there exist more detailed approaches for classifying types of flood processes, including the use of various process indicators (e.g. flood timing, storm duration, rainfall depth, snowmelt, catchment states), as suggested by Merz and Blöschl (2003). The classification proposed here, however, is very easy to apply and fully suitable for our analyses, given the broad distinction between rainfall and snowmelt flood generation that we are using in this work. In addition, the required runoff components can be readily extracted from the output of the HBV model.

Events were identified using a tool implemented in the $\mathrm{R}$ add-on package seriesdist (https://bitbucket.org/heisterm/ seriesdist), which enables the detection of both flood peaks and their event-specific flood duration. In order to also account for the antecedent conditions in the catchment, the detected flood duration time of the core event was extended by adding the catchment-specific recession time (found in the definition of the normal flood duration) before the onset of the flood. The classification approach was then applied to the extended flood duration time such that all relevant contributions to the peak flow are considered.

Two statistics were applied to identify changes in the FGPs: (1) the ratios of rainfall-, rainfall + snowmelt- and snowmelt-generated events relative to all events for all ensemble realizations were estimated for the reference and future periods. The change in the ratios indicates the changes in the prevalence of the different FGPs. (2) Circular kernel density functions and the circular mean Julian date of occurrence 
of the rainfall-, rainfall + snowmelt- and snowmelt-generated events were calculated for both periods to illustrate changes in the annual distribution and mean timing of the events. The circular mean Julian dates of occurrence for the events with respect to each FGP are converted to mean radians $(\bar{\Theta})$ estimated from the Julian date of occurrence $D$ for each event $i$ :

$\Theta_{i}=\frac{D 2 \pi}{365}$,

where the Julian date $D=1$ is for 1 January and $D=365$ for 31 December. The $\bar{x}$ and $\bar{y}$ coordinates for the mean date as an angular value are derived from the sample of $n$ events for each FGP group:

$$
\begin{aligned}
& \bar{x}=\frac{1}{n} \sum_{i=1}^{n} \cos \Theta_{i}, \\
& \bar{y}=\frac{1}{n} \sum_{i=1}^{n} \sin \Theta_{i}, \\
& \bar{\Theta}=\tan ^{-1}\left(\frac{\bar{y}}{\bar{x}}\right) .
\end{aligned}
$$

This approach was introduced by Bayliss and Jones (1993) and Burn (1997), and has been recently applied by Parajka et al. (2010) and Köplin et al. (2014). Note that these authors also estimate the variability of the date of occurrence. In this study, this is illustrated using the circular kernel density functions.

\subsection{Sources of uncertainty}

The range of all ensemble realizations provides a measure of the overall uncertainty represented by the ensemble, given that each projection is assumed to be equally likely. Similar to Déqué et al. $(2007,2011)$, the mean variance $\overline{\sigma^{2}}$ ensemble (as a measure of uncertainty) of the entire ensemble is here defined as the additive mean variances from the ensemble components:

${\overline{\sigma^{2}}}_{\text {ensemble }}={\overline{\sigma^{2}}}_{\mathrm{GCM} / \mathrm{RCM}}+{\overline{\sigma^{2}}}_{\mathrm{LAM}}+{\overline{\sigma^{2}}}_{\mathrm{HP}}$.

We exemplify the computation of mean variances from the ensemble components for the hydrological model parameterization $\left(\overline{\sigma^{2}} \mathrm{HP}\right)$ : for each combination $i$ out of $n$ possible combinations of GCM/RCMs and LAMs, we compute the variance $\sigma_{\mathrm{HP}, i}$ subject to 25 parameter sets of the hydrological model. Then, we compute $\overline{\sigma^{2}} \mathrm{HP}$ as the mean over all $\sigma_{\mathrm{HP}, i \ldots n}, \bar{\sigma}^{2} \mathrm{GCM} / \mathrm{RCM}$ and $\bar{\sigma}^{2} \mathrm{LAM}$ are computed accordingly.

This approach was used to identify the fractional uncertainty emerging from the different sources within the model chain for three variables: (i) the change in the index $S_{\mathrm{D}}$, (ii) the change in the median magnitude of the POT events, and (iii) the change in the fraction of snowmelt- over rainfallgenerated events.

\section{Results and discussion}

\subsection{Model and ensemble validation}

The performance of the HBV model is validated using the 25 best-fit parameter sets to estimate POT events during the reference period. These are compared with the distribution of observed POT events for the same period. In this case, the HBV simulations are based on observed meteorological data. Furthermore, we evaluated the ability of the entire ensemble (i.e. including all GCM/RCM combinations, LAMs, and hydrological parameter sets) to match the observed POT events for the reference period. A further comparison was made with HBV simulations based on the raw RCM data and the adjusted RCM data to assess the potential benefit of the adjustment procedures. The distribution of the POT events for each of these options is illustrated in Fig. 2.

The results indicate that the HBV model using the 25 bestfit parameter sets with observed climate data reproduces the observed POT events reasonably well for almost all of the catchments. For Junkerdalselv, the underestimation of the distribution of observed POT events is considerably larger than in other catchments. Junkerdalselv also has the lowest $\mathrm{NSE}_{w}$ value (0.77), which is due to systematic underestimation of flood peaks by the calibrated model. The $\mathrm{NSE}_{w}$ value for the other five catchments varies from 0.83 (Fustvatn) to 0.91 (Atnasjø).

As expected, the absolute range and the interquartile range of the POT event distribution from the full ensemble are larger. This mainly results from the large range introduced by the locally adjusted climate projections (see the fourth and fifth box in each plot). In four catchments the quartiles match the observed distribution fairly well (Krinsvatn, Øvrevatn, Atnasjø, Kråkfoss). The largest discrepancies occur for Fustvatn and Junkerdalselv. In both cases, the mismatch of the ensemble reflects the overestimation (Fustvatn) and underestimation (Junkerdalselv) resulting from the different LAMs. Nevertheless, the observed distributions of POT events are always captured by the full range of the ensemble and the data locally adjusted by EQM and XDS. The performance of the ensemble in reproducing the observed POT events is the only indicator we have of how reliable the ensemble is for future projections. For Fustvatn and Junkerdalselv, this implies a lower degree of reliability as compared with the remaining catchments.

Figure 2 also underlines the benefit of locally adjusting raw RCM data for hydrological simulations. The simulations iii-v are based on only one best-fit HBV parameter set assuring that the ranges in the distribution of the events are solely based on the range of the input data. The large ranges in the distribution of the simulations based on RCM raw data are narrowed considerably after adjustment at Øvrevatn, Junkerdalselv, Atnasjø and Kråkfoss by both LAMs. Moreover, the LAMs are able to correct the large discrepancies in the POT event distributions for the observed vs. the simulated 


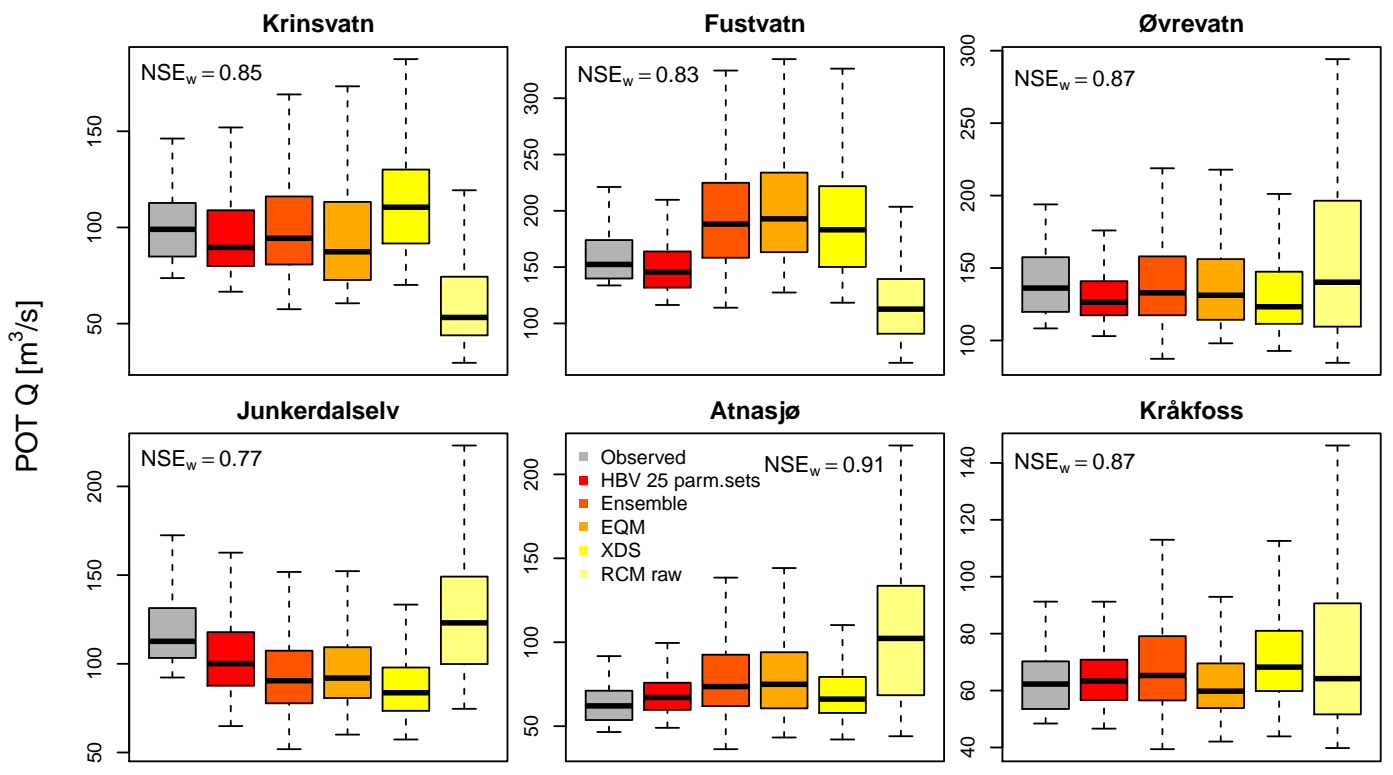

Figure 2. The distributions of POT events for the reference period from observed (grey) and simulated streamflow series generated by the calibrated HBV model using (from left to right) (i) observed climate data with the 25 best-fit parameter sets, (ii) the entire ensemble (i.e. all GCM/RCM combinations, LAMs, and hydrological parameter sets), (iii) the data locally adjusted by EQM, (iv) the data locally adjusted by XDS, and (v) the raw RCM data. For the simulations (iii-v) only one best-fit HBV parameter set is considered. The NSE $w$ values given for each catchment represent the goodness of fit of the HBV model for the entire series (not only POT events) using the best parameter set identified by the calibration. Note that the ordinate's point is not 0 and differs between the single plots.

series for Krinsvatn, Fustvatn and Atnasjø. For Fustvatn, the benefit of the local adjustment is least since the underestimation of the RCM raw data is only corrected to an overestimation of almost the same magnitude and range. It is not possible to conclude which of the two LAMs is better suited for high-flow estimations, neither in general nor for specific catchments.

\subsection{Changes in the temperature and precipitation regime}

Figure 3 summarizes the interquartile ranges of the projected changes in mean temperature and precipitation sums for the spring/summer and autumn/winter seasons after local adjustment by EQM and XDS for the six study catchments.

Increasing median temperatures from $2.9^{\circ} \mathrm{C}$ (Krinsvatn, spring/summer) to $4.8^{\circ} \mathrm{C}$ (Øvrevatn, autumn/winter) are projected for both seasons and all catchments considered. The temperature projections indicate a larger warming in autumn/winter than in spring/summer in all catchments, which agrees with Engen-Skaugen et al. (2007) and Hanssen-Bauer et al. (2003, 2009). Moreover, the largest warming is found for the northernmost catchments (Øvrevatn and Junkerdalselv) both for the spring/summer and autumn/winter periods. Generally, the results reflect findings from previous studies indicating an increasing warming signal with larger distances in latitudinal and longitudinal directions (Engen-Skaugen et al., 2007; Hanssen-Bauer et al., 2003). With the exception of
Kråkfoss, the interquartile ranges for the spring/summer season are higher as compared to the autumn/winter season for all catchments.

Regarding precipitation, the medians show increasing precipitation sums for both seasons and all catchments considered. The increase in spring/summer precipitation tends to be larger than autumn/winter precipitation at Krinsvatn, Fustvatn, Øvrevatn and Junkerdalselv. For Atnasjø and Kråkfoss the increase in precipitation during autumn/winter is projected to be larger than during spring and summer. The increase in autumn/winter precipitation in these two catchments is the largest projected change in precipitation $(>+30 \%)$ found within this study. Despite the positive median values, the ensemble does not consistently show positive changes in the projections. The first quartile for the changes in autumn/winter precipitation indicates decreasing precipitation sums for Krinsvatn, Fustvatn, Øvrevatn and Junkerdalselv. For Atnasjø and Kråkfoss the first quartile of the distribution indicates decreasing spring/summer precipitation sums. Generally, the results for these six catchments correspond to the regional differences in seasonal precipitation change previously presented in Hanssen-Bauer et al. (2009).

\subsection{Changes in flood seasonality}

Figure 4 summarizes the results for the index $S_{\mathrm{D}}$ for the reference and future period for the six study catchments. The boxplots represent the full ensemble. 

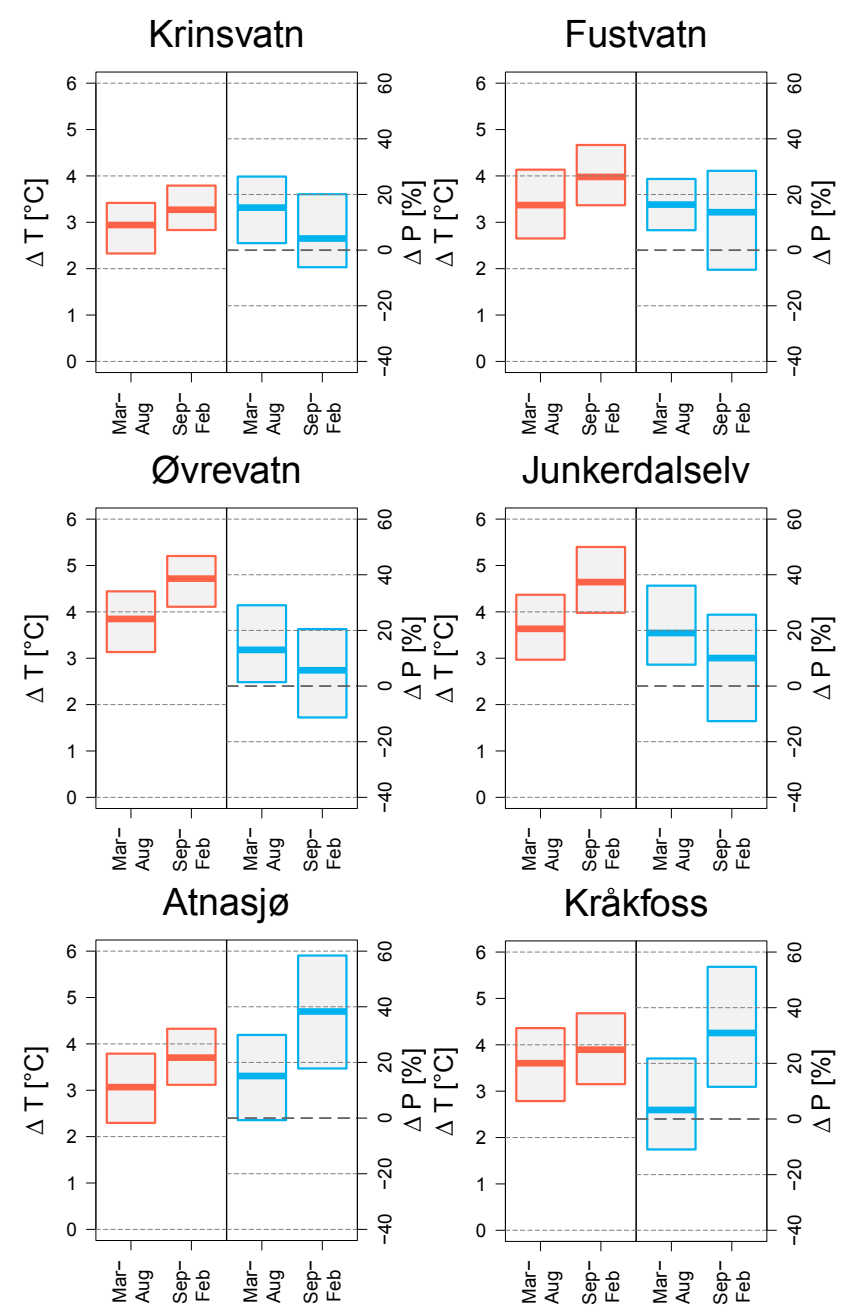

Figure 3. The interquartile ranges of the projected changes from the reference (1961-1990) to the future period (2071-2099) in mean temperature (left panel) and precipitation sums (right panel) for the spring/summer and autumn/winter seasons as they are locally adjusted by EQM and XDS for the six study catchments.

For the reference period, the $S_{\mathrm{D}}$ quartiles for the coastal catchments Krinsvatn and Fustvatn show positive values, indicating a dominance of autumn/winter POT events under the current climate. For Øvrevatn and Junkerdalselv in the north, as well as for Atnasjø and Kråkfoss in central and south-eastern Norway, the $S_{\mathrm{D}}$ quartiles indicate dominant POT events during spring/summer. The dominance of spring/summer events is largest for Atnasjø, but Junkerdalselv also shows a distinct spring/summer pattern with negative $S_{\mathrm{D}}$ values for all ensemble realizations. For Kråkfoss, this dominance is least pronounced. The observed flood seasonality (indicated by the green bars) is matched reasonably well in five of the six catchments (Krinsvatn, Fustvatn, Øvrevatn, Junkerdalselv, Atnasjø), with Fustvatn and Øvrevatn having the best matches. For Kråkfoss, however, the $S_{\mathrm{D}}$ values for the majority of the ensemble realizations are rather low suggesting that the dominance of spring/summer events is exaggerated to some degree by the model simulations. Simulated $S_{\mathrm{D}}$ values based on observed meteorological input data and the 25 best-fit parameter sets were, however, found to be very similar to the $S_{\mathrm{D}}$ value based on observed runoff (not shown). Thus, the overestimation of spring/summer events at Kråkfoss is a consequence of climate input data, rather than the hydrological modelling.

For the future period, the $S_{\mathrm{D}}$ values are higher for all catchments. That means that the importance of autumn/winter events is projected to increase in all catchments considered. The lowest impact is found for Atnasjø where the dominance of spring/summer events persists into the future. However, for $\emptyset_{v r e v a t n}$ and Kråkfoss considerably higher $S_{\mathrm{D}}$ values indicate a possible seasonal shift in the flood regimes since $S_{\mathrm{D}}$ becomes positive for almost the entire interquartile of all ensemble realizations. Changes towards dominant autumn/winter events are also indicated for some ensemble members for Junkerdalselv. However, the first and second quartiles still show negative $S_{\mathrm{D}}$ values.

The ranges in the projections given by the boxplots illustrate the uncertainty associated with the ensemble. For the reference period, this is highest for Fustvatn and Kråkfoss. For the future period, the highest ranges are found for $\emptyset_{v r e-}$ vatn, Junkerdalselv and Kråkfoss, which show the largest change in flood seasonality. Note that the projected changes in seasonality are significant (with $95 \%$ confidence) for all catchments, as none of the notches of the boxplots for the reference and future periods are overlapping.

\subsection{Changes in the magnitude vs. the frequency of events}

After having detected changes in flood seasonality, the question arises as to whether these result from changes in flood magnitude vs. frequency in the two respective seasons. Figure 5 summarizes the POT events for all ensemble realizations according to their associated magnitudes and number of occurrences for the two seasons.

For the coastal catchments, Krinsvatn and Fustvatn, Fig. 5 shows that both the relative number and the magnitude of POT events increase in autumn/winter during the future period. For spring/summer the magnitude also increases but the frequency decreases (i.e. the blue boxes show smaller widths). Together, this explains the intensification of the seasonality index $S_{\mathrm{D}}$ towards autumn/winter events. The seasonal shift towards autumn/winter events is even more pronounced for the northernmost catchments, Øvrevatn and Junkerdalselv (Fig. 4). Figure 5 indicates that this shift is mostly due to changes in the frequency (increasing in autumn/winter, decreasing in spring/summer) while the mean magnitudes are decreasing in both seasons. Note, however, that the observed seasonal POT magnitudes are not well reproduced by the ensemble for Junkerdalselv. For the highaltitude catchment in central Norway, Atnasjø, Fig. 4 indi- 

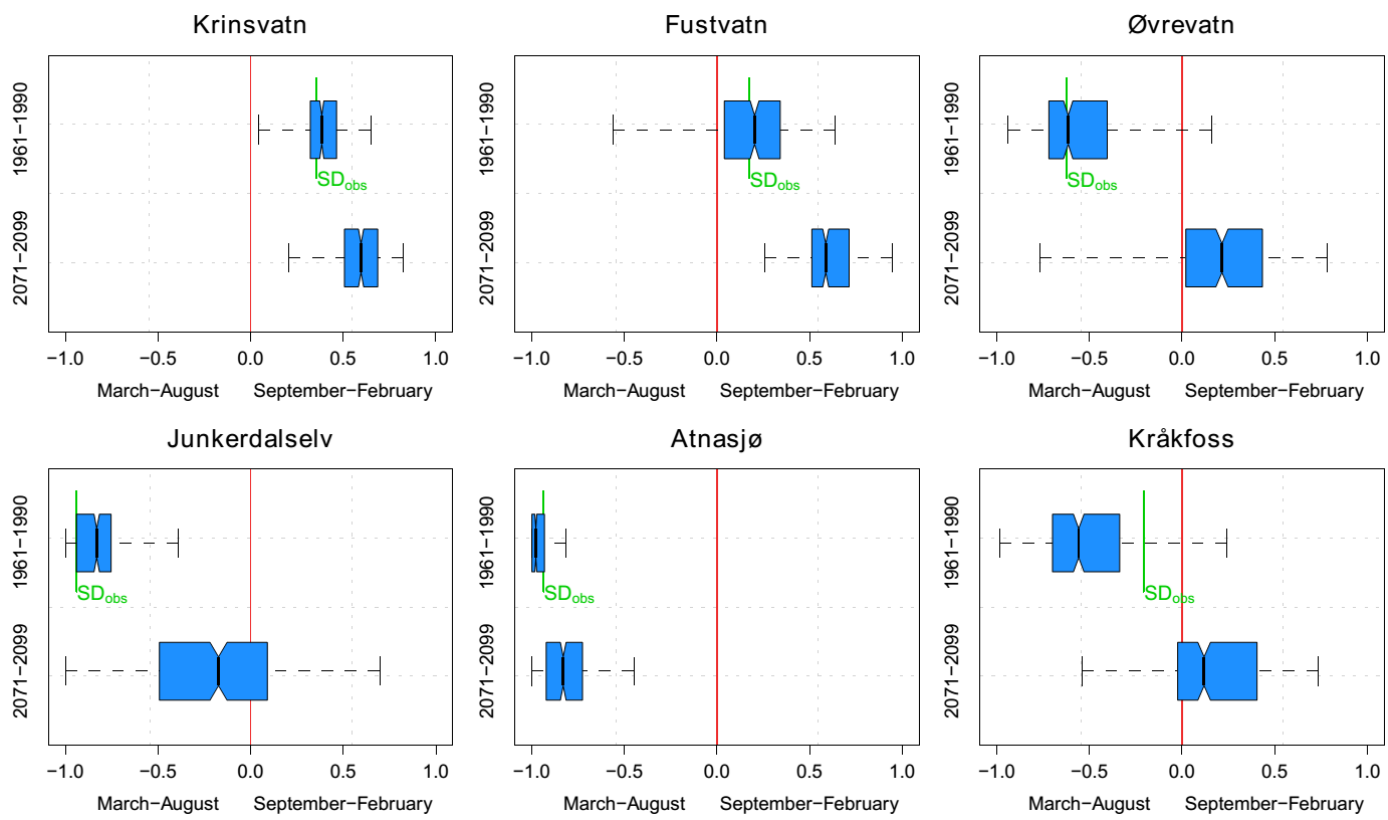

Figure 4. Boxplots showing the seasonality index $S_{\mathrm{D}}$ for all ensemble realizations for the reference and future periods. The boxes show the interquartile of the values; the whiskers show the full range of the projections. The green bars in the upper panel of each plot $\left(S_{\mathrm{D}_{\mathrm{obs}}}\right)$ indicate the observed seasonality index $S_{\mathrm{D}}$.

cates that spring/summer events are very dominant in both the current and future climates. Figure 5 establishes that this dominance reflects the frequency of the events in the POT series, and not necessarily the magnitude. Future flood magnitudes increase slightly for both seasons, while frequencies increase particularly in the autumn/winter period. This is responsible for the slight shift in seasonal index in Fig. 4. Finally, Fig. 5 also illustrates that the large seasonal shift for Kråkfoss is caused by both frequencies (decrease in spring/summer, increase in autumn/winter) and magnitudes. Future flood magnitudes increase in both seasons, but the increase in autumn/winter is considerably larger.

Note that the discrepancies between the observed and simulated POT magnitudes for the reference period (i.e. Fig. 2) are also reflected in the seasonal values in Fig. 5. The large discrepancy at Junkerdalselv (underestimation) and Atnasjø (overestimation) for the autumn/winter period is due to the limited number of observed events during these months. The correspondence between the observed and simulated seasonal median POT event magnitudes at Kråkfoss is comparatively better than for the seasonality index $S_{\mathrm{D}}$ (Fig. 4). Since the distribution of the POT event magnitudes are very similar both for the spring/summer and the autumn/winter seasons, the bias of $S_{\mathrm{D}}$ towards spring/summer results from an overestimation of the event frequency for this season.

The median changes in the POT event magnitudes from the references to the future period are significant (with $95 \%$ confidence) for all catchments, as none of the illustrated notches for the respective period is overlapping.

\subsection{Changes in FGPs}

In the previous sections, we established that autumn/winter events will become more dominant in the future. This is consistent over all investigated catchments, although there are differences with respect to their underlying causes (i.e. changes in frequency, magnitude, or both). In general, we would expect that an increasing dominance of autumn/winter events corresponds to an increasing importance of rainfall as a FGP. Figure 6 shows how the percentage of different flood generating processes will change between the reference and the future periods.

Rainfall becomes the dominant FGP in the future period in all investigated catchments. For the coastal catchments, Krinsvatn and Fustvatn, where rainfall already dominates flood generation in the current climate, it will become even more important in the future. Snowmelt-generated floods, which play only a minor role in these catchments during the reference period, will be non-existent by the end of the 21 st century. In the remaining four catchments, rainfall replaces snowmelt as the dominant FGP. The largest increases in the importance of rainfall are projected for the northernmost catchments, Øvrevatn and Junkerdalselv, and the southeastern catchment, Kråkfoss, where the changes in flood seasonality are also highest. This confirms that changes in flood seasonality are closely connected to changes in the FGPs and supports the conclusion of Köplin et al. (2014), who also found that the most pronounced changes in flood seasonality under a future climate will occur in catchments which are snowmelt-dominated during the current climate. 

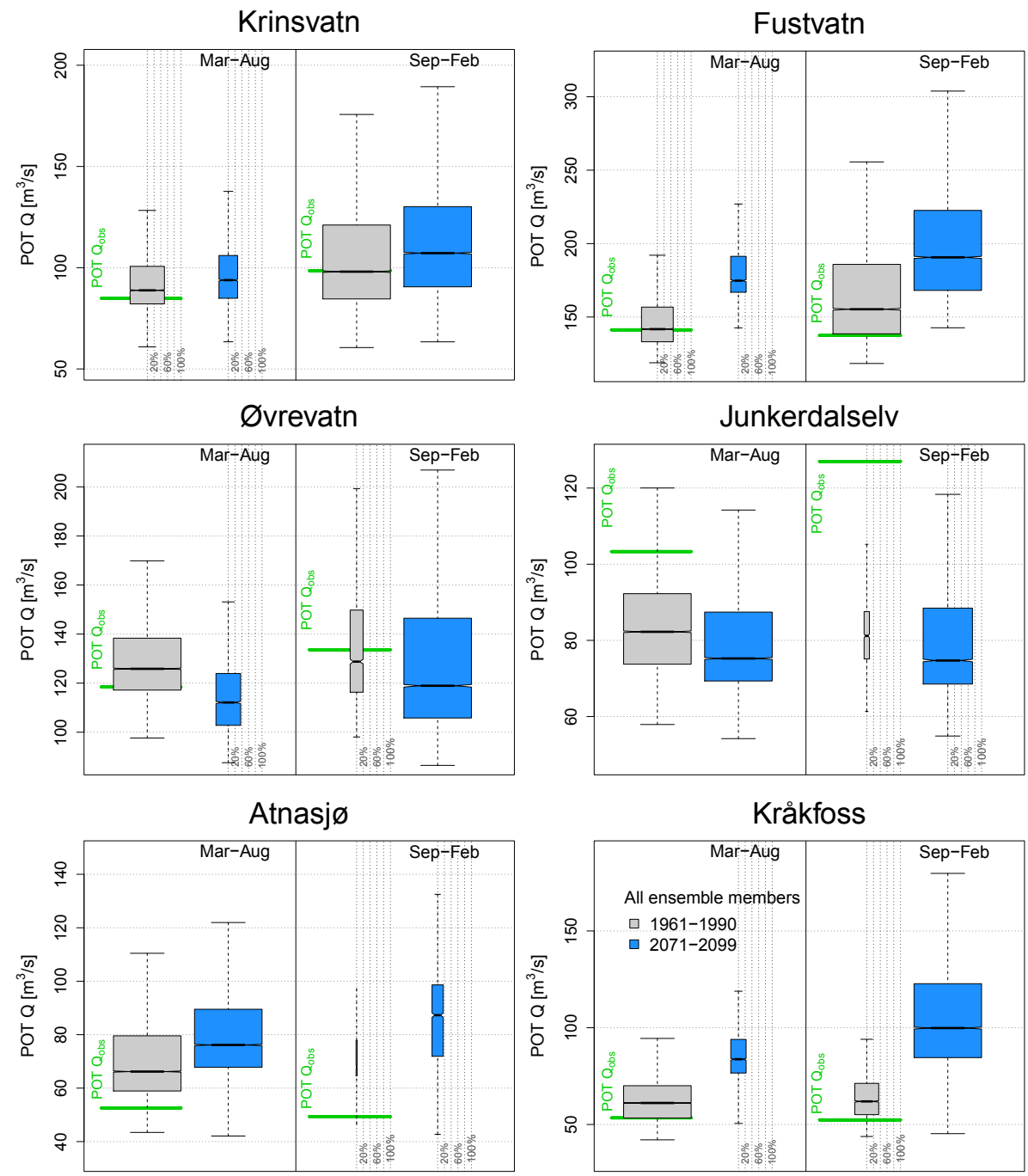

Figure 5. Boxplots showing the median and interquartile magnitudes of the simulated POT events from all ensemble realizations for the reference (grey boxes) and future periods (blue boxes), separated with respect to the two basic flood seasons in Norway (spring/summer left panels; autumn/winter - right panels). The whisker range corresponds to twice the interquartile range. The green bars (POT ${ }_{\text {obs }}$ ) indicate the median magnitudes of observed POT events. The width of the boxes illustrates the seasonal distribution in the frequency of the POT events: Per catchment and period, the smaller boxes are scaled compared to the larger boxes representing the dominant flood season in terms of flood frequency.

Figure 7 shows the circular kernel density functions of the events for each FGP and illustrates the relationship between the changes in the FGPs and the median magnitude of the events as a function of their mean Julian date of occurrence.

Snowmelt-associated events are connected with an earlier timing and POT events of a decreased magnitude in catchments where this FGP continues to be relevant in the generation of high flows. Higher mean temperatures in the future period (Fig. 3) lead to an earlier onset of the annual snowmelt season. For the catchments which continue to have peak discharges derived from snowmelt in the future period, the circular mean Julian dates of occurrence of the snowmeltgenerated events is estimated to be 14-26 days earlier com- pared to the reference period: Øvrevatn (26 days), Junkerdalselv (21days), Atnasjø (14 days), Kråkfoss (22 days). This agrees with similar findings from streamflow observations and projections for the Nordic countries (Beldring et al., 2008; Stahl et al., 2010; Wilson et al., 2010) and for other parts of Europe and the world (e.g. Déry et al., 2009; Kormann et al., 2014; Renner and Bernhofer, 2011; Stewart et al., 2005; Hall et al., 2014, and reference list therein). With the exception of Kråkfoss, the mean magnitude of snowmeltgenerated POT events will decrease in all catchments where snowmelt has an influence on flooding in the future period. This is because of smaller snowpack volumes due to shorter 
Krinsvatn

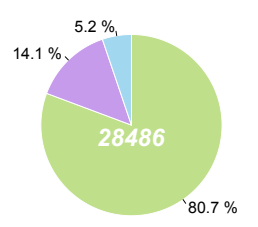

\section{Øvrevatn}
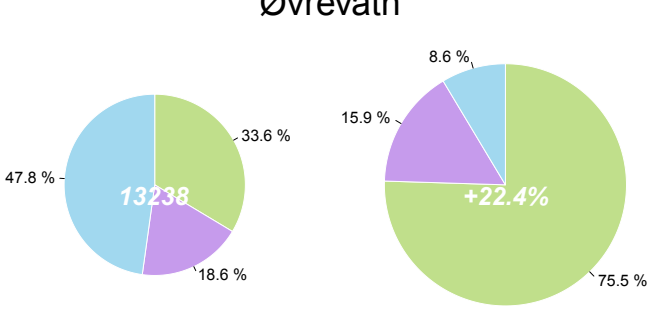

Atnasjø

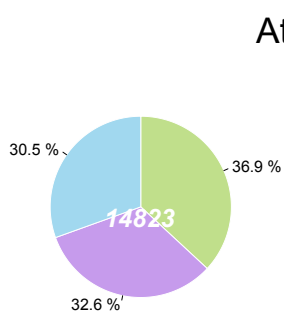

$1961-1990$

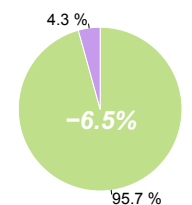

90

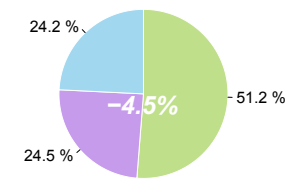

$2071-2100$

Fustvatn

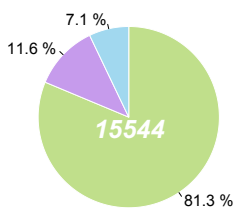

Junkerdalselv

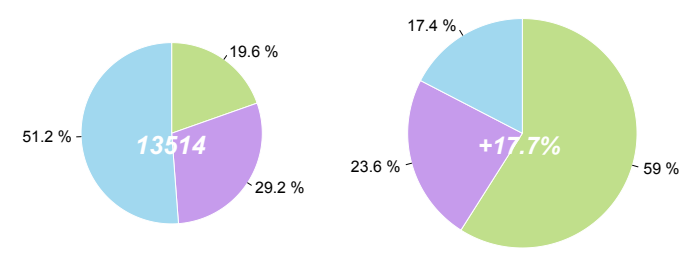

Kråkfoss

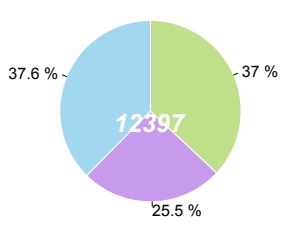

$1961-1990$
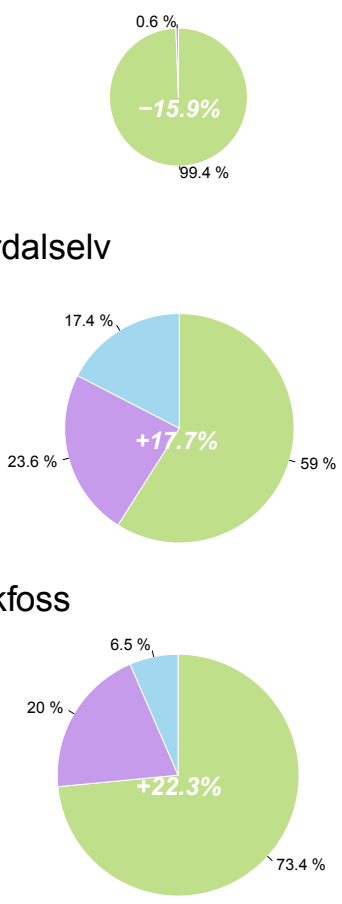

$2071-2100$

\section{rainfall rainfall+snowmelt snowmelt}

Figure 6. Percentage of POT events according to their FGPs in relation to the total number of events for the reference (left pie charts) and future periods (right pie charts) derived by all ensemble realizations. The diameter of the pie charts for the future period indicates the direction of change in the total number of events. Total numbers of events for the reference period and the percentage of change in the number of events for the future period are given by the white numbers within the pie charts.

and warmer winters in the future period (Vikhamar Schuler et al., 2006).

Rainfall-generated events tend to occur later within the year across all catchments. The later mean timing of rainfallgenerated events highlights the increasing importance of winter rainfall floods in the future period. This corresponds to projected changes in the temperature and precipitation regimes (Fig. 3), which lead to a shorter snow season and reduced snow storage, and to an increasing relevance of episodes with intermittent rainfall and winter snowmelt due to higher winter temperatures (Hanssen-Bauer et al., 2009). For Øvrevatn, Junkerdalselv and Kråkfoss, this suggests that winter precipitation is no longer primarily received as snowfall such that the contribution of snowmelt to runoff is considerably less in the future period. Thus, the strongest changes in flood seasonality are observed for these three catchments which is in line with Arnell (1999), who concludes that the most significant changes in flow regimes occur where snowfall becomes less important due to higher temperatures. The effects of increased evaporation during late summer due to higher temperatures may also amplify the later mean timing of rainfall-generated events, as soil moisture deficits may have a more pronounced role in attenuating heavy rainfalls during the autumn period.

The mean magnitudes of rainfall-generated events are projected to increase at Fustvatn, Atnasjø and Kråkfoss which explains the increasing POT-event magnitudes during autumn and winter in these catchments as shown in Fig. 5. The increasing magnitudes of autumn/winter events at Krinsvatn (Fig. 5) result from an earlier circular mean timing of the rainfall + snowmelt-generated events in the future period (from March to February) rather than from larger rainfallgenerated POT-event magnitudes during autumn and winter (Fig. 7). The circular density functions show that rainfall has an influence on flooding throughout the year, particularly during autumn and winter for both the reference and future periods. Prominent seasonal peaks of rainfall-generated events during the reference period, as observed for Kråkfoss (October-November), will be smoothed in the future period. Thus, rainfall becomes more relevant for spring and summer, as well as winter events in the future period. 

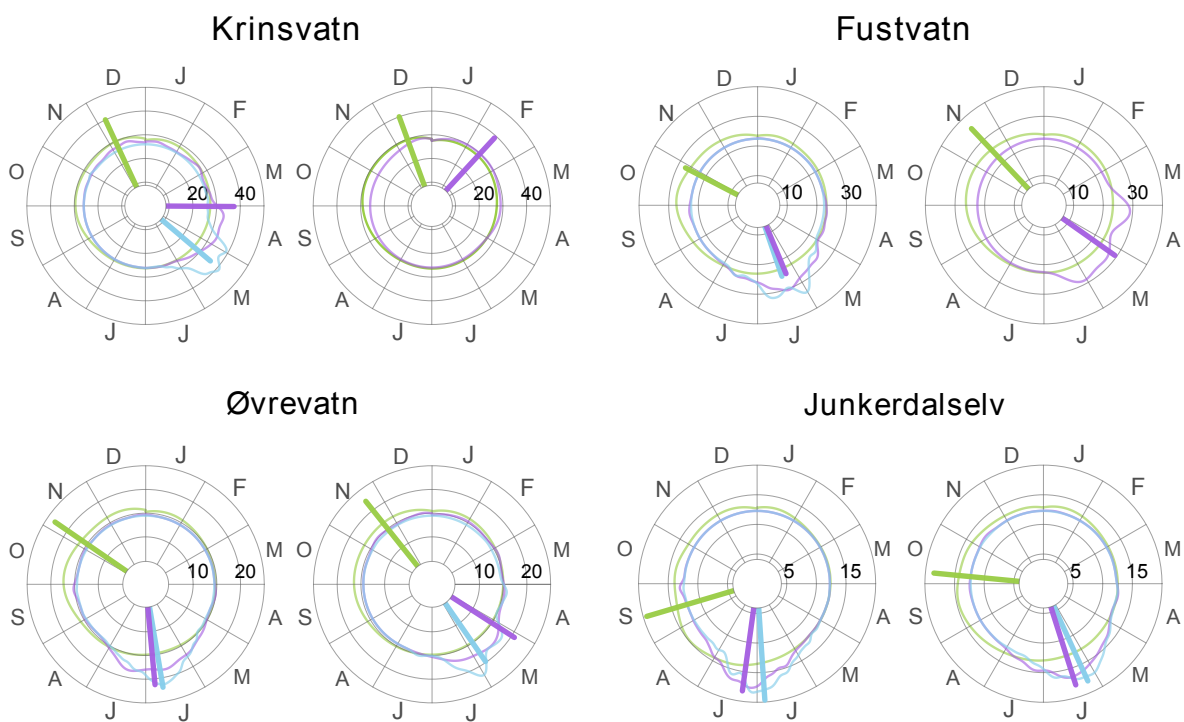

revatn
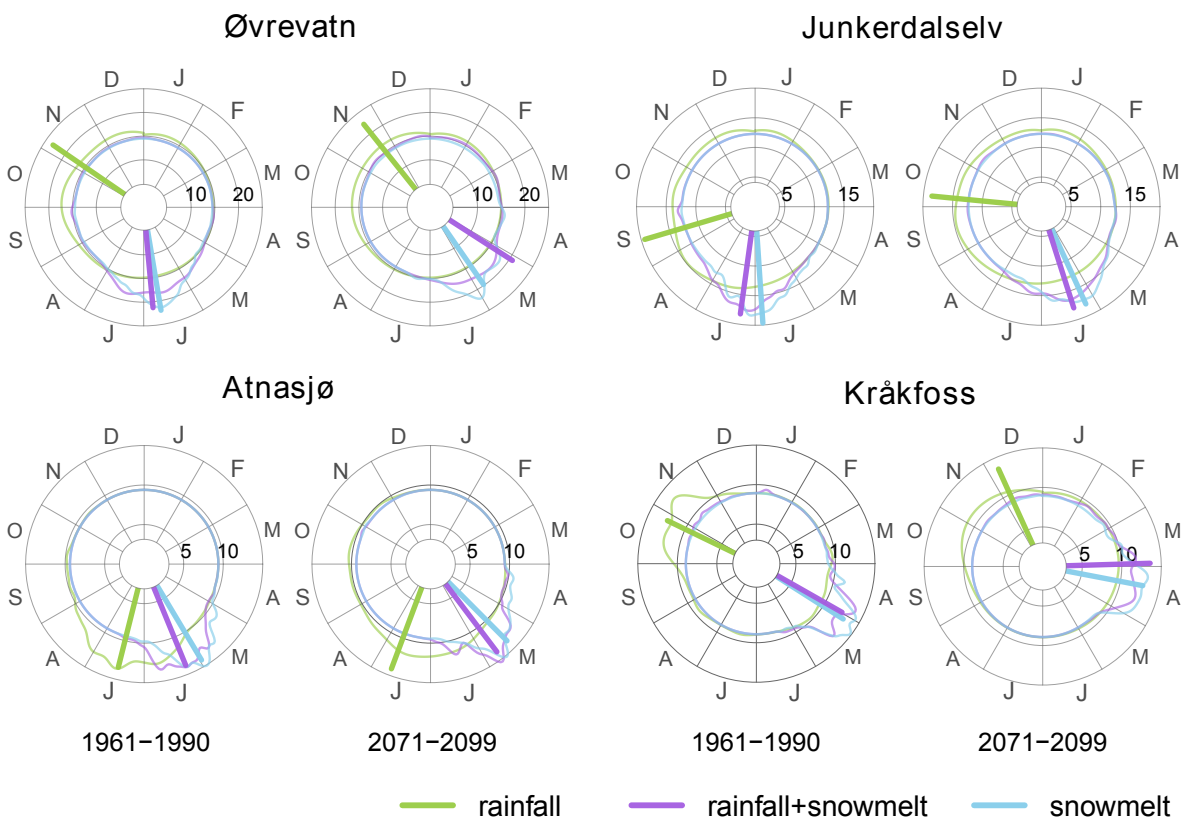

Figure 7. Circular plots showing (i) the circular kernel density function of the simulated POT events according to their FGPs (normalized; no units), and (ii) the median POT-event magnitude ( $\mathrm{mm} \mathrm{day}^{-1}$ ) as bars according to their circular mean Julian date of occurrence and their FGPs for the reference and future periods.

The results also illustrate that changes in flood seasonality cannot be directly inferred from seasonal changes in precipitation and temperature. Hydrological modelling is required to highlight the changing role of snow storage and its effect on flood generation.

\subsection{Contribution of ensemble components to uncertainty}

Figure 8 shows the fractional variance from the different sources of the ensemble as they contribute to the total variance regarding the changes in the index $S_{\mathrm{D}}$, the POT magnitudes and the FGPs presented in Figs. 4-7.

First of all, the GCM/RCM combinations and the LAMs are the dominant sources of uncertainty for all catchments and variables considered. Hydrological model parameterization tends to be the smallest contributor to overall uncertainty, which is in line with earlier studies (e.g. Wilby and Harris, 2006; Kay et al., 2008; Prudhomme and Davies, 2008; Dobler et al., 2012b). Note, however, that there are exceptions where the variance due to the hydrological model parameterization is as high as that due to the LAMs or the climate projections (i.e. Junkerdalselv, second and third columns). Focusing on the target variables, hydrological parameter uncertainty tends to be less important for changes in the seasonality index $S_{\mathrm{D}}$ as compared with changes in the POT-event magnitudes and the dominant FGPs.

A possible pattern becomes apparent regarding the relative role of hydrological parameter uncertainty, which seems to be closely connected to the changes in flood seasonality and FGPs. Hydrological parameter uncertainty is rather high in those catchments for which a considerable change in their flood seasonality and the FGPs is expected (Øvrevatn, Junkerdalselv, Kråkfoss). This is probably due to changes in the dominant flood generation mechanisms. It is likely that the parameter sets, which are calibrated for the climate conditions in the entire reference period, are not sufficiently stable given the likely changes in hydroclimatological and runoff generation processes under future conditions. This highlights the difficulties associated with transferring model parameters in time under non-stationary conditions (Brigode et al., 

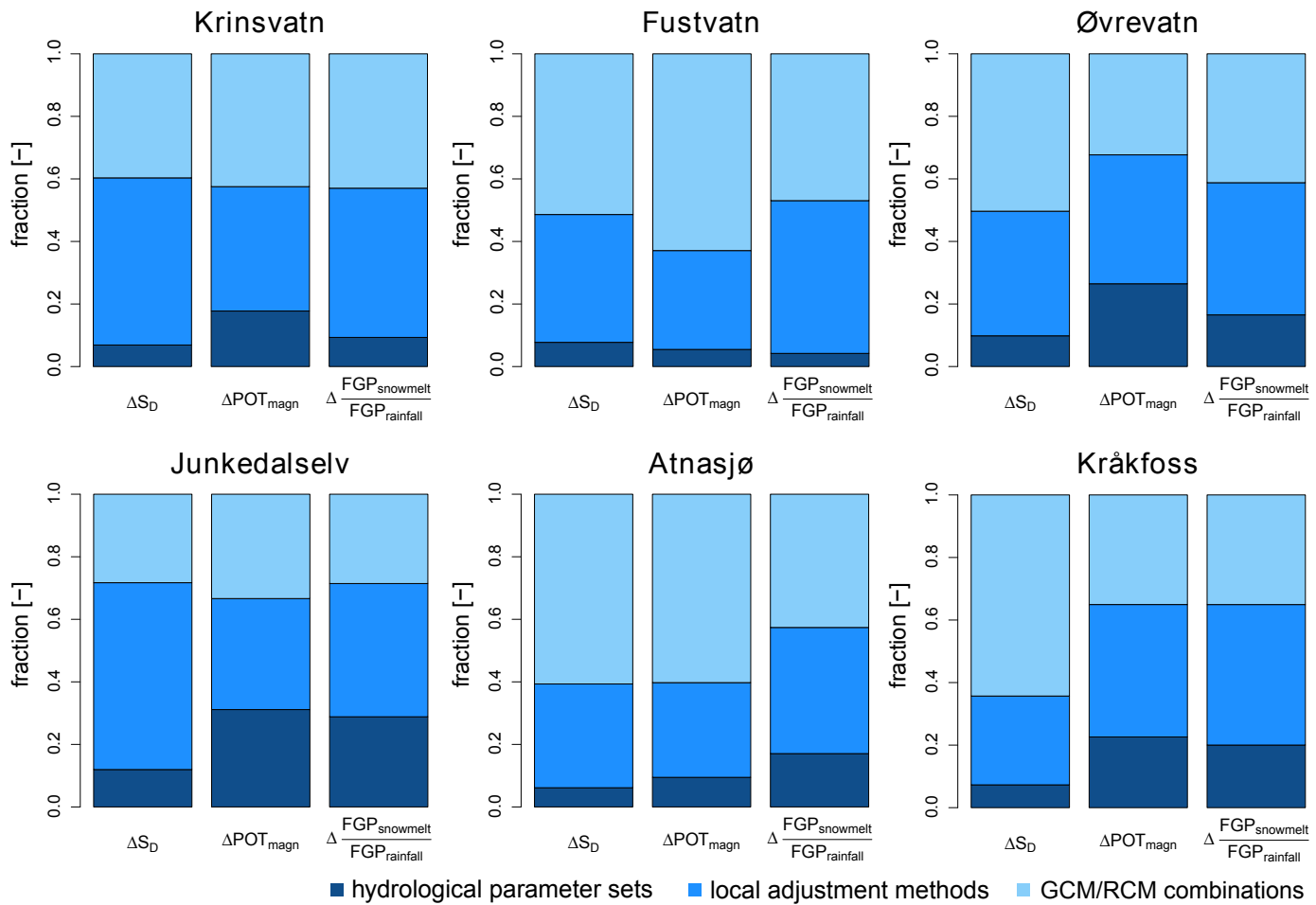

- local adjustment methods $\quad$ GCM/RCM combinations

Figure 8. The fractions of total variance (-) as a measure for uncertainty, explained by (i) the GCM/RCM combinations (light blue), (ii) the local adjustment methods (medium blue), and (iii) the hydrological parameterization (dark blue) with respect to three target variables: (1) change in the seasonality index $S_{\mathrm{D}}$, (2) change in the mean POT event magnitude, and (3) change in the ratio of snowmelt- and rainfallgenerated POT events.

2013; Merz et al., 2011). The choice of the reference period (1961(1966)-1990) may imply that we have detected quite stable parameters for that period since the pronounced warming during the recent years are not included in the calibration. These parameters, however, may be even less representative for the future conditions. Merz et al. (2011) have calibrated a similar version of the HBV model for six consecutive 5-year periods for a comprehensive set of catchments in Austria. They found notable time trends in the calibrated parameters representing snow dynamics and soil moisture processes which lead to considerable biases especially in high flows. For our results, that implies that the hydrological model parameter uncertainty limits the reliability of the estimated changes in the proportion of rainfall and snowmelt and their effects on flood seasonality and FGPs.

One option for dealing with that issue are differential split sample tests (Klemeš, 1986). These are usually used to evaluate parameter sets which are optimized for contrasting conditions. Seibert (2003) calibrated the HBV model in four Swedish catchments on years with lower runoff peaks and tested the calibrated parameters for years with higher peaks, finding a decrease in model performance. Coron et al. (2012) introduced generalized split-sample tests, which systematically test all possible combinations of calibrationvalidation periods using a 10 -year moving window over the observation time period. They also pointed out a lack of robustness in hydrological model parameters tested in climate conditions which differ to those used for model calibration. Similar schemes need to be adapted for seasonality purposes, i.e. identifying contrasting periods in terms of seasonal flood prevalence and dominant FGPs. Differential split sample testing can then indicate parameter robustness when applied under contrasting seasonality conditions. They may also indicate parameter sets which are suitable for runoff simulations under future conditions. This approach, however, presupposes that relevant changes can already be detected in the observation data and that contrasting periods are long enough for a sufficient model calibration.

\section{Conclusions}

Using a multi-model/multi-parameter ensemble approach, the impacts of climate change on flood seasonality and their underlying flood generating processes (FGPs) have been investigated in six catchments representing different hydroclimatological regions in Norway. 
The results indicate that the HBV model, including the use of 25 best-fit parameter sets, is able to reproduce observed distributions of flood events reasonably well for five out of six study catchments for the reference period. Small discrepancies between the event distributions simulated by the locally adjusted climate projection data and the observed event distributions slightly reduce the reliability of the ensemble setup for two catchments (Fustvatn, Junkerdalselv). For the remaining four catchments the ensemble reproduces the observed flood-event distributions fairly well. The benefit of post-processing the RCM raw data has also been demonstrated. However, no distinct ranking emerged regarding the performance of the two LAMs applied.

Reconsidering our research questions, the following conclusions can be drawn:

- How might the existing patterns of flood seasonality change under a future climate? Autumn/winter floods become more important in all the catchments considered. For the two coastal catchments that suggests an intensification of the current autumn/winter flood regime. For the high-mountain catchment, Atnasjø, in central Norway, the dominance of spring/summer floods will be slightly reduced. For the northernmost catchments, Øvrevatn and Junkerdalselv, as well as for the south-eastern catchment, Kråkfoss, the increase in autumn/winter floods is largest and may lead to a systematical shift in the current flood regimes from spring/summer to autumn/winter.

- How are the shifts in seasonality related to changes in the magnitude vs. changes in the frequency of events? Changes in flood seasonality from spring/summer towards autumn/winter are the result of increasing event magnitudes or frequencies, or a combination of both, during the autumn and winter months. Changes in seasonal frequency, however, are more relevant than changes in seasonal magnitude since two of the catchments with the strongest changes in flood seasonal-

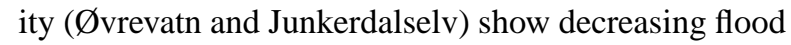
magnitudes but large shifts in the seasonal frequency of events.

- Are changes in flood seasonality associated with changes in the FGPs? The change towards more autumn/winter events corresponds to an increasing relevance of rainfall as a FGP. Rainfall becomes more dominant where it has already been dominant and it replaces snowmelt as the dominant FGP in the remaining catchments. The largest increases in the relative role of rainfall correspond with the largest shifts in flood seasonality ( $\varnothing$ vrevatn, Junkerdalselv, Kråkfoss). In these catchments, less snow accumulation and shorter snow seasons due to increased winter temperatures lead to a considerable decrease in the frequency and magnitude of snowmelt-generated events. Additionally, rainfall- generated events occur more often and also later within the autumn/winter period. Thus, the largest changes in the FGPs are closely connected with temperature effects which determine the relative role of snowmelt vs. rainfall. This has a major influence on the seasonal distribution of floods.

- What is the relative importance of the different ensemble components in contributing to the overall variance as a measure of the uncertainty in the projected changes? For changes in flood seasonality the ensemble range is largest in those catchments for which the largest seasonal changes are projected. The climate projections (i.e. the GCM/RCM combinations) or the LAMs tend to be the largest contributor to the total variance. However, the relative role of the hydrological model parameterization compared to the other two contributors is highest for those catchments showing the most pronounced seasonal changes. This is consistent with an earlier study of climate change impacts in four Norwegian catchments (Lawrence and Haddeland, 2011), and confirms the lack of robustness in HBV parameterizations for simulations with transient hydroclimatological conditions which lead to changes in the flood regime. It further stresses the need for alternative calibration approaches which improve the transferability of hydrological model parameters under non-stationary conditions.

Although the catchments analysed within this study represent a large variety of climate conditions in Norway, the sample size is too small to allow for robust regional conclusions on changes in the seasonality and generation processes of floods. The results presented here can only indicate possible responses to climate change in terms of flood seasonality and FGPs for catchments with similar hydroclimatological regimes and physical conditions. For robust regional conclusions, the proposed methodology needs to be applied for a larger sample of catchments. Alternatively, a grid-based modelling approach covering the whole country could also be used, although such results must be interpreted with care in areas lacking data for model calibration.

Acknowledgements. The first author acknowledges the Helmoltz graduate research school GeoSim for funding the PhD studentship and NVE for funding study visits to Norway. The second author acknowledges support from NVE for the internally funded project Climate change and future floods. The regional climate model simulations stem from the EU FP6 project ENSEMBLES, whose support is gratefully acknowledged. Gerd Bürger (University of Potsdam) is thanked for his great support on downscaling the RCM data by XDS. The Potsdam Graduate School (PoGS) is acknowledged for supporting the service charge cover for this open access publication. Daniel Viviroli and two anonymous referees are thanked for their comments on an earlier version of this manuscript.

Edited by: R. Merz 


\section{References}

Andréasson, J. and Bergström, S.: Hydrological change-climate change impact simulations for Sweden, AMBIO A J. Hum. Environ., 33, 228-234, doi:10.1579/0044-7447-33.4.228, 2004.

Arnell, N. W.: The effect of climate change on hydrological regimes in Europe: a continental perspective, Global Environ. Change, 9, 5-23, doi:10.1016/S0959-3780(98)00015-6, 1999.

Bayliss, A. C. and Jones, R. C.: Peaks-Over-Threshold Flood Database: Summary Statistics and Seasonality, Wallingford, UK, 1993.

Beldring, S., Engen-Skaugen, T., Førland, E. J., and Roald, L. A.: Climate change impacts on hydrological processes in Norway based on two methods for transferring regional climate model results to meteorological station sites, Tellus A, 60, 439-450, doi:10.1111/j.1600-0870.2008.00306.x, 2008.

Benestad, R. E.: Association between trends in daily rainfall percentiles and the global mean temperature, J. Geophys. Res.Atmos., 118, 10802-10810, doi:10.1002/jgrd.50814, 2013.

Beniston, M., Stephenson, D. B., Christensen, O. B., Ferro, C. A. T., Frei, C., Goyette, S., Halsnaes, K., Holt, T., Jylhä, K., Koffi, B., Palutikof, J., Schöll, R., Semmler, T., and Woth, K.: Future extreme events in European climate: an exploration of regional climate model projections, Climatic Change, 81, 71-95, doi:10.1007/s10584-006-9226-z, 2007.

Bergström, S.: Development and application of a conceptual runoff model for Scandinavian catchments, Report No. 7 RHO, Swedish Meteorological and Hydrological Institute - SMHI, Nörrköping, 1976.

Bergström, S.: The HBV model, in: Computer Models of Watershed Hydrology, edited by: Singh, V. P., Water Resources Publications, Highlands Ranch, CO, 443-476, 1995.

Bhend, J. and von Storch, H.: Consistency of observed winter precipitation trends in northern Europe with regional climate change projections, Clim. Dynam., 31, 17-28, doi:10.1007/s00382-0070335-9, 2007.

Blöschl, G., Viglione, A., Merz, R., Parajka, J., Salinas, J. L., and Schöner, W.: Auswirkungen des Klimawandels auf Hochwasser und Niederwasser, Österreichische Wasser- und Abfallwirtschaft, 63, 21-30, doi:10.1007/s00506-010-0269-z, 2011.

Boé, J., Terray, L., Habets, F., and Martin, E.: Statistical and dynamical downscaling of the Seine basin climate for hydro-meteorological studies, Int. J. Climatol., 27, 1643-1655, doi:10.1002/joc.1602, 2007.

Brigode, P., Oudin, L., and Perrin, C.: Hydrological model parameter instability: A source of additional uncertainty in estimating the hydrological impacts of climate change?, J. Hydrol., 476, 410-425, doi:10.1016/j.jhydrol.2012.11.012, 2013.

Bronstert, A., Kolokotronis, V., Schwandt, D., and Straub, H.: Comparison and evaluation of regional climate scenarios for hydrological impact analysis?: General scheme and application example, Int. J. Climatol., 1594, 1579-1594, doi:10.1002/joc.1621, 2007.

Bürger, G.: Expanded downscaling for generating local weather scenarios, Clim. Res., 7, 111-128, doi:10.3354/cr007111, 1996.

Bürger, G., Reusser, D., and Kneis, D.: Early flood warnings from empirical (expanded) downscaling of the full ECMWF Ensemble Prediction System, Water Resour. Res., 45, W10443, doi:10.1029/2009WR007779, 2009.
Burn, D. H.: Catchment similarity for regional flood frequency analysis using seasonality measures, J. Hydrol., 202, 212-230, doi:10.1016/S0022-1694(97)00068-1, 1997.

Chen, J., Brissette, F. P., and Leconte, R.: Uncertainty of downscaling method in quantifying the impact of climate change on hydrology, J. Hydrol., 401, 190-202, doi:10.1016/j.jhydrol.2011.02.020, 2011.

Coron, L., Andréassian, V., Perrin, C., Lerat, J., Vaze, J., Bourqui, M., and Hendrickx, F.: Crash testing hydrological models in contrasted climate conditions: An experiment on 216 Australian catchments, Water Resour. Res., 48, W05552, doi:10.1029/2011WR011721, 2012.

Déqué, M., Rowell, D. P., Lüthi, D., Giorgi, F., Christensen, J. H., Rockel, B., Jacob, D., Kjellström, E., Castro, M., and Hurk, B.: An intercomparison of regional climate simulations for Europe: assessing uncertainties in model projections, Climatic Change, 81, 53-70, doi:10.1007/s10584-006-9228-x, 2007.

Déqué, M., Somot, S., Sanchez-Gomez, E., Goodess, C. M., Jacob, D., Lenderink, G., and Christensen, O. B.: The spread amongst ENSEMBLES regional scenarios: regional climate models, driving general circulation models and interannual variability, Clim. Dynam., 38, 951-964, doi:10.1007/s00382-011-1053-x, 2011.

Déry, S. J., Stahl, K., Moore, R. D., Whitfield, P. H., Menounos, B., and Burford, J. E.: Detection of runoff timing changes in pluvial, nival, and glacial rivers of western Canada, Water Resour. Res., 45, W04426, doi:10.1029/2008WR006975, 2009.

Dobler, C., Bürger, G., and Stötter, J.: Assessment of climate change impacts on flood hazard potential in the Alpine Lech watershed, J. Hydrol., 460-461, 29-39, doi:10.1016/j.jhydrol.2012.06.027, 2012a.

Dobler, C., Hagemann, S., Wilby, R. L., and Stötter, J.: Quantifying different sources of uncertainty in hydrological projections in an Alpine watershed, Hydrol. Earth Syst. Sci., 16, 4343-4360, doi:10.5194/hess-16-4343-2012, 2012b.

Dobler, C., Bürger, G., and Stötter, J.: Simulating future precipitation extremes in a complex Alpine catchment, Nat. Hazards Earth Syst. Sci., 13, 263-277, doi:10.5194/nhess-13-263-2013, 2013.

Dyrrdal, A. V., Isaksen, K., Hygen, H., and Meyer, N.: Changes in meteorological variables that can trigger natural hazards in Norway, Clim. Res., 55, 153-165, doi:10.3354/cr01125, 2012.

Dyrrdal, A. V., Saloranta, T., Skaugen, T., and Stranden, H. B.: Changes in snow depth in Norway during the period 1961-2010, Hydrol. Res., 44, 169, 169-179, doi:10.2166/nh.2012.064, 2013.

Engen-Skaugen, T., Haugen, J. E., and Tveito, O. E.: Temperature scenarios for Norway: from regional to local scale, Clim. Dynam., 29, 441-453, doi:10.1007/s00382-007-0241-1, 2007.

Fleig, A. K., Andreassen, L. M., Barfod, E., Haga, J., Haugen, L. E., Hisdal, H., Melvold, K., and Saloranta, T.: Norwegian Hydrological Reference Dataset for Climate Change Studies, Report No. 2, Norwegian Water Resources and Energy Directorate - NVE, Oslo, 2013.

Fowler, H. J. and Ekström, M.: Multi-model ensemble estimates of climate change impacts on UK seasonal precipitation extremes, Int. J. Climatol., 29, 385-416, doi:10.1002/joc.1827, 2009.

Fowler, H. J., Blenkinsop, S., and Tebaldi, C.: Linking climate change modelling to impacts studies: recent advances in downscaling techniques for hydrological modelling, Int. J. Climatol., 27, 1547-1578, doi:10.1002/joc.1556, 2007. 
Gottschalk, L., Jensen Jørgen, L., Lundquist, D., Solantie, R., and Tollan, A.: Hydrologic Regions in the Nordic Countries, Nord. Hydrol., 10, 273-286, 1979.

Gudmundsson, L.: qmap: Statistical transformations for postprocessing climate model output, $\mathrm{R}$ package version 1.0-3, http:// cran.r-project.org/web/packages/qmap/citation.html (last access: February 2015), 2014.

Gudmundsson, L., Bremnes, J. B., Haugen, J. E., and EngenSkaugen, T.: Technical Note: Downscaling RCM precipitation to the station scale using statistical transformations - a comparison of methods, Hydrol. Earth Syst. Sci., 16, 3383-3390, doi:10.5194/hess-16-3383-2012, 2012.

Hall, J., Arheimer, B., Borga, M., Brázdil, R., Claps, P., Kiss, A., Kjeldsen, T. R., Kriaučiūnienè, J., Kundzewicz, Z. W., Lang, M., Llasat, M. C., Macdonald, N., McIntyre, N., Mediero, L., Merz, B., Merz, R., Molnar, P., Montanari, A., Neuhold, C., Parajka, J., Perdigão, R. A. P., Plavcová, L., Rogger, M., Salinas, J. L., Sauquet, E., Schär, C., Szolgay, J., Viglione, A., and Blöschl, G.: Understanding flood regime changes in Europe: a state-of-the-art assessment, Hydrol. Earth Syst. Sci., 18, 27352772, doi:10.5194/hess-18-2735-2014, 2014.

Hanssen-Bauer, I., Achberger, C., Benestad, R. E., Chen, D., and Førland, E. J.: Statistical downscaling of climate scenarios over Scandinavia, Clim. Res., 29, 255-268, 2005.

Hanssen-Bauer, I., Drange, H., Førland, E., Roald, L. A., Børsheim, K. Y., Hisdal, H., Lawrence, D., Nesje, A., Sandven, S., Sorteberg, A., Sndby, S., Vasskog, K., and Ådlandsvik, B.: Klima i Norge 2100 Bakgrunnsmateriale til NOU Klimatilpasning Climate in Norway 2100 background material for NOU climate adaptation, Norsk klimasenter, Oslo, 2009.

Hanssen-Bauer, I., Førland, E. J., Haugen, J. E., and Tveito, O. E.: Temperature and precipitation scenarios for Norway: comparison of results from dynamical and empirical downscaling, Clim. Res., 25, 15-27, 2003.

IPCC: Special Report on Emission Scenarios - Summary for Policymakers, Cambridge University Press, Cambridge, UK, 2000.

IPCC: Climate Change 2007: The Physical Science Basis, edited by: Solomon, S., Qin, D., Manning, M., Chen, Z., Marquis, M., Averyt, K. B., Tignor, M., and Miller, H. L., Cambridge University Press, Cambridge, UK, and New York, NY, USA, 2007.

Kay, a. L., Davies, H. N., Bell, V. A., and Jones, R. G.: Comparison of uncertainty sources for climate change impacts: flood frequency in England, Climatic Change, 92, 41-63, doi:10.1007/s10584-008-9471-4, 2008.

Klemeš, V.: Operational testing of hydrological simulation models, Hydrolog. Sci. J., 31, 13-24, doi:10.1080/02626668609491024, 1986.

Köplin, N., Schädler, B., Viviroli, D., and Weingartner, R.: Seasonality and magnitude of floods in Switzerland under future climate change, Hydrol. Process., 28, 2567-2578, doi:10.1002/hyp.9757, 2014.

Kormann, C., Francke, T., and Bronstert, A.: Detection of regional climate change effects on alpine hydrology by daily resolution trend analysis in Tyrol, Austria, J. Water Clim. Change, doi:10.2166/wcc.2014.099, in press, 2014.

Lang, M., Ouarda, T. B. M. J., and Bobée, B.: Towards operational guidelines for over-threshold modeling, J. Hydrol., 225, 103117, doi:10.1016/S0022-1694(99)00167-5, 1999.
Lawrence, D. and Haddeland, I.: Uncertainty in hydrological modelling of climate change impacts in four Norwegian catchments, Hydrol. Res., 42, 457-471, doi:10.2166/nh.2011.010, 2011.

Lawrence, D. and Hisdal, H.: Hydrological projections for floods in Norway under a future climate, Report No. 5, Norwegian Water Resources and Energy Directorate - NVE, Oslo, 2011.

Maraun, D., Wetterhall, F., Ireson, A., Chandler, R., Kendon, E., Widmann, M., Brienen, S., Rust, H., Sauter, T., Themessl, M., Venema, V., Chun, K., Goodess, C., Jones, R., Onof, C., Vrac, M., and Thiele-Eich, I.: Precipitation Downscaling Under Climate Change: Recent Developments To Bridge the Gap Between Dynamical Models and the End User, Rev. Geophys., 48, 1-34, 2010.

Merz, R. and Blöschl, G.: A process typology of regional floods, Water Resour. Res., 39, 1340, doi:10.1029/2002WR001952, 2003.

Merz, R., Parajka, J., and Blöschl, G.: Scale effects in conceptual hydrological modeling, Water Resour. Res., 45, W09405, doi:10.1029/2009WR007872, 2009.

Merz, R., Parajka, J., and Blöschl, G.: Time stability of catchment model parameters: Implications for climate impact analyses, Water Resour. Res., 47, W02531, doi:10.1029/2010WR009505, 2011.

Midttømme, G. H., Petterson, L. E., Holmqvist, E., Nøtsund, Ø., Hisdal, H., and Sivertsgård, R.: Retningslinjer for flomberegninger - Guidelines for flood estimation, Retningslinjer nr. 5, Norwegian Water Resources and Energy Directorate - NVE, Oslo, 2011.

Parajka, J., Kohnová, S., Bálint, G., Barbuc, M., Borga, M., Claps, P., Cheval, S., Dumitrescu, A., Gaume, E., Hlavčová, K., Merz, R., Pfaundler, M., Stancalie, G., Szolgay, J., and Blöschl, G.: Seasonal characteristics of flood regimes across the Alpine-Carpathian range, J. Hydrol., 394, 78-89, doi:10.1016/j.jhydrol.2010.05.015, 2010.

Petterson, L. E.: Aktive vannføringsstasjoner i Norge - Active streamflow gauges in Norway, Rapport nr. 16, Norwegian Water Resources and Energy Directorate - NVE, Oslo, 2004.

Piani, C., Haerter, J. O., and Coppola, E.: Statistical bias correction for daily precipitation in regional climate models over Europe, Theor. Appl. Climatol., 99, 187-192, doi:10.1007/s00704-0090134-9, 2009.

Prudhomme, C. and Davies, H.: Assessing uncertainties in climate change impact analyses on the river flow regimes in the UK, Part 2: future climate, Climatic Change, 93, 197-222, doi:10.1007/s10584-008-9461-6, 2008.

R Core Team: R: A language and environment for statistical computing, Foundation for Statistical Computing, Vienna, Austria, 2012.

Renner, M. and Bernhofer, C.: Long term variability of the annual hydrological regime and sensitivity to temperature phase shifts in Saxony/Germany, Hydrol. Earth Syst. Sci., 15, 1819-1833, doi:10.5194/hess-15-1819-2011, 2011.

Roald, L. A.: Climate change impacts on streamflow in Norway, Consultancy report A no. 1, Norwegian Water Resources and Energy Directorate - NVE, Oslo, 2006.

Sælthun, N.: The Nordic HBV model, Publication no. 7, Norweian Water Resources and Endergy Directorate - NVE, Oslo, 1996.

Seibert, J.: Reliability of Model Predictions Outside Calibration Conditions, Nord. Hydrol., 34, 477-492, 2003. 
Seneviratne, S. I., Nicholls, N., Easterling, D. R., Goodess, C. M., Kanae, S., Kossin, J., Luo, Y., Marengo, J., McInnes, K., Rahimi, N., Reichstein, M., Sorteberg, A., Vera, C., and Zhang, $\mathrm{X}$.: Changes in climate extremes and their impacts on the natural physical environment, in: Managing the Risks of Extreme Events and Disasters to Advance Climate Change Adaptation, edited by: Field, C. B., Barros, V., Stocker, T. F., Qin, D., Dokken, D. J., Ebi, K., Mastrandrea, D. M., Mach, K. J., Plattner, G.-K., Allen, S. K., Tignor, M., and Midgley, G. F., Cambridge University Press, Cambridge, UK, and New York, NY, USA, 109-230, 2012.

Stahl, K., Hisdal, H., Hannaford, J., Tallaksen, L. M., van Lanen, H. A. J., Sauquet, E., Demuth, S., Fendekova, M., and Jódar, J.: Streamflow trends in Europe: evidence from a dataset of nearnatural catchments, Hydrol. Earth Syst. Sci., 14, 2367-2382, doi:10.5194/hess-14-2367-2010, 2010.

Stewart, I. T., Cayan, D. R., and Dettinger, M. D.: Changes toward Earlier Streamflow Timing across Western North America, J. Climate, 18, 1136-1155, doi:10.1175/JCLI3321.1, 2005.

Sunyer, M. A., Madsen, H., Rosbjerg, D., and Arnbjerg-Nielsen, K.: Regional interdependency of precipitation indices across Denmark in two ensembles of high resolution RCMs, J. Climate, 26, 7912-7928, doi:10.1175/JCLI-D-12-00707.1, 2013.

Teutschbein, C. and Seibert, J.: Bias correction of regional climate model simulations for hydrological climate-change impact studies: Review and evaluation of different methods, J. Hydrol., 456457, 12-29, doi:10.1016/j.jhydrol.2012.05.052, 2012.

Tollan, A.: Hydrologiske regioner i Norden, Vannet i Nord., 1, 1-41, 1975.

Tolson, B. A. and Shoemaker, C. A.: Dynamically dimensioned search algorithm for computationally efficient watershed model calibration, Water Resour. Res., 43, W01413, doi:10.1029/2005WR004723, 2007.

Uppala, S. M., Kållberg, P. W., Simmons, A. J., Andrae, U., Bechtold, V. D. C., Fiorino, M., Gibson, J. K., Haseler, J., Hernandez, A., Kelly, G. A., Li, X., Onogi, K., Saarinen, S., Sokka, N., Allan, R. P., Andersson, E., Arpe, K., Balmaseda, M. A., Beljaars, A. C. M., Van De Berg, L., Bidlot, J., Bormann, N., Caires, S., Chevallier, F., Dethof, A., Dragosavac, M., Fisher, M., Fuentes, M., Hagemann, S., Hólm, E., Hoskins, B. J., Isaksen, L., Janssen, P. A. E. M., Jenne, R., Mcnally, A. P., Mahfouf, J.-F., Morcrette, J.-J., Rayner, N. A., Saunders, R. W., Simon, P., Sterl, A., Trenberth, K. E., Untch, A., Vasiljevic, D., Viterbo, P., and Woollen, J.: The ERA-40 re-analysis, Q. J. Roy. Meteorol. Soc., 131, 2961-3012, doi:10.1256/qj.04.176, 2005.
Van der Linden, P. and Mitchell, J. F. B.: ENSEMBLES: Climate Change and its Impacts: Summary of research and results from the ENSEMBLES project, M. O. H. Centre, Exeter, UK, 2009.

van Roosmalen, L., Sonnenborg, T. O., Jensen, K. H., and Christensen, J. H.: Comparison of Hydrological Simulations of Climate Change Using Perturbation of Observations and Distribution-Based Scaling, Vadose Zone J., 10, 136-150, doi:10.2136/vzj2010.0112, 2011.

Veijalainen, N., Lotsari, E., Alho, P., Vehviläinen, B., and Käyhkö, J.: National scale assessment of climate change impacts on flooding in Finland, J. Hydrol., 391, 333-350, doi:10.1016/j.jhydrol.2010.07.035, 2010.

Velázquez, J. A., Schmid, J., Ricard, S., Muerth, M. J., Gauvin StDenis, B., Minville, M., Chaumont, D., Caya, D., Ludwig, R., and Turcotte, R.: An ensemble approach to assess hydrological models' contribution to uncertainties in the analysis of climate change impact on water resources, Hydrol. Earth Syst. Sci., 17, 565-578, doi:10.5194/hess-17-565-2013, 2013.

Vikhamar Schuler, D., Beldring, S., Førland, E. J., Roald, L. A., and Engen-Skaugen, T.: Snow cover and snow water equivalent in Norway: current conditions (1961-1990) and scenarios for the future (2071-2100), met.no report no. 1, Norwegian Meteorological Institute - met.no, Oslo, 2006.

Wilby, R. L. and Harris, I.: A framework for assessing uncertainties in climate change impacts: Low-flow scenarios for the River Thames, UK, Water Resour. Res., 42, W02419, doi:10.1029/2005WR004065, 2006.

Wilson, D., Hisdal, H., and Lawrence, D.: Has streamflow changed in the Nordic countries? - Recent trends and comparisons to hydrological projections, J. Hydrol., 394, 334-346, doi:10.1016/j.jhydrol.2010.09.010, 2010. 